\title{
A proton transfer compound template phenylethylamine: synthesis, a collective experimental and theoretical investigations
}

\author{
Sofian Gatfaoui (a), Noureddine Issaoui (b), Thierry Roisnel ${ }^{(\mathrm{c})}$ and Houda Marouani (a) \\ (a) Laboratory of Material Chemistry, Faculty of Sciences of Bizerte, University of Carthage, 7021 Zarzouna, \\ Tunisia \\ (b) Laboratoire de physique quantique et statistique, Faculté des Sciences de Monastir, Université de Monastir, \\ Monastir 5079, Tunisia \\ (c) Centre de Diffractométrie X, UMR 6226 CNRS, Unité Sciences Chimiques de Rennes, Université de Rennes \\ I, 263 Avenue du Général Leclerc, 35042 Rennes, France
}

\begin{abstract}
Synthesis, crystalline architecture, vibrational spectroscopy, thermal analysis, electrical behavior and detailed theoretical DFT studies has been reported for the new inorganicorganic hybrid material phenylethylammonium trioxonitrate with general chemical formula $\left(\mathrm{C}_{6} \mathrm{H}_{5}\left(\mathrm{CH}_{2}\right)_{2} \mathrm{NH}_{3}\right) \mathrm{NO}_{3}$ (PEAN). The determination of crystal structures plays an significant to understanding weak, intra and intermolecular, interactions that great influence crystal packing. PEAN has been crystallized to the monoclinic system with space group $\mathrm{P} 2{ }_{1} / \mathrm{c}$ and the network parameters obtained are $a=5.9497(8) \AA, b=20.494(3) \AA, c=8.4528(11) \AA, \beta=113$. $812(8)^{\circ}, \mathrm{V}=942.9(2) \AA^{3}$ and $\mathrm{Z}=4$. The atomic arrangement of the PEAN compound can be described by 3D framework. The organic cations are linked to the nitrate anions by means of an assortment of $\mathrm{N}-\mathrm{H} \cdots \mathrm{O}$ hydrogen bonding trapped in layers at $\mathrm{y}=1 / 4$ and $3 / 4$. These layers are interrelated via $\mathrm{C}-\mathrm{H} \ldots \pi$ interactions involving organic cations, an infinite chain are consequently created along the $c$-axis. Hirshfeld surfaces and 2D fingerprint plots estimate the weak intermolecular interactions accountable for the generation of crystal packing. The structural propriety and vibrational spectral analyze of PEAN have been investigated by using DFT calculations at B3LYP/6-311++G(d,p) level of theory. Intermolecular interactions were studied by NBO and AIM analyses. Thermal analysis (TG-DTA and DSC) and dielectric conductivity was also investigated. These measurements were realized to discuss the observed phase transition mechanism in the vicinity of $340 \mathrm{~K}$.
\end{abstract}

Keywords: Crystal structure, Hirshfeld surface analysis, AIM, NBO, dielectric conductivity. 


\section{Introduction}

Organic-inorganic hybrid materials have been increasingly attracted to recent research, hence the synergy between the thermal, electrical and/or optical properties of inorganic entities and the physico-chemical properties of organic materials through different interactions, electrostatic, non-bonding and van der Waals interactions penetrate several application fields such as biology [1,2], medicine [3], photo catalysis [4], also these hybrid materials flood the fields of optics and optoelectronics [5]. Phenylethylamine (PEA) is a monoaminated alkaloid that occurs in the nervous system of humans and other mammals, functioning as a transmitting neurohormone or a neurohormone moderator that maintains energy, attention and humor. This monoamine classified as a natural and physiological treatment against depression, for this reason studies and observations clinical have been made and show that (PEA) (at the dose of $10 \mathrm{mg}$ once or twice a day) is effective in $60 \%$ of the patients. Its encounter with conventional antidepressant drugs has no adverse consequences like weight gain and sexual inhibition. (PEA) is structurally similar to amphetamine, it produces pharmacological effects and widely used in optical resolutions. (PEA) levels are shown to be very low in the biological fluids of depressed patients. Biochemically, PEA plays the role of an excitatory neurotransmitter and organizes neuronal potentials to promote glutamate activity and trigger neurotransmitters [6-8]. As part of our current study, we report our investigations on a new organic-inorganic hybrid compound: Phenylethylammonium nitrate with general chemical formula $\left(\mathrm{C}_{6} \mathrm{H}_{5}\left(\mathrm{CH}_{2}\right)_{2} \mathrm{NH}_{3}\right) \mathrm{NO}_{3}$ (PEAN). Within this context chemical preparation, structural study and geometric optimization associate with an insight into Hirshfeld surface analysis are discussed. In addition, theoretical analyzes have been carried out along this work, which considerably enrich the available knowledge about the material, namely the vibrational properties, as well as the topological properties AIM [9] and orbital NBO [10]. The dielectric and thermal analysis study are also discussed.

\section{Experimental}

\subsection{Materials and physical measurements}

Measurements of X-ray diffracted intensities were recorded at $150 \mathrm{~K}$ using a diffractometer Bruker-AXS APEXII, working at molibdene wavelength $(\lambda=0.71073 \AA)$. Absorption corrections were carried out by the multi-scan technique by the means of SADABS program [11]. Among the 6632 reflections measured only 2159 are independent, the remainder (1539) had an intensity I $>2 \sigma(\mathrm{I})$. The direct methods using the SIR97 program were used to solve the structure [12]. The structure was, and then, refined with full-matrix least-square methods based on $F^{2}$ (SHELXL-97) [13] through the assist of the WINGX 
program [14]. All non-hydrogen atoms were refined by means of anisotropic atomic displacement parameters. All the hydrogen atoms linked to carbon atoms were located in calculated positions and refined by the way of fixed individual displacement parameters $[\mathrm{Uiso}(\mathrm{H})=1.2 \mathrm{Ueq}]$ awarded to the riding model $(\mathrm{C}-\mathrm{H}$ (aromatic, methylene) bond lengths of $0.93 \AA$ and $0.97 \AA$, respectively). The remained hydrogen atoms were located in a difference map.

A final refinement on $F^{2}$ converged at $R\left(F^{2}\right)=0.049$ and $w R\left(F^{2}\right)=0.125$. In Table 1 we have recorded: the parameters used for the X-ray data, the strategy for the crystal structure determination and its final results. Fig. 1a illustrate an ORTEP [14] drawing of the molecular structure. Infrared (IR) spectrum, in the 4000-400 $\mathrm{cm}^{-1}$ region, was collected at room temperature by the means on a Nicolet IR 200 FTIR spectrophotometer. Thermal analysis, from room temperature up to $850 \mathrm{~K}$, was realized using a multimodule 92 Setaram analyzer. This later, operate at an average heating rate of $5 \mathrm{~K} / \mathrm{min}$. In this study, the mass of the simple used was $5.63 \mathrm{mg}$ for DTA/TG and $6.8 \mathrm{mg}$ for DSC. An open circuit using two electrode configurations in the band of frequency ranging from $5 \mathrm{~Hz}$ to $13 \mathrm{MHz}$ and with signal amplitude of $50 \mathrm{mV}$ were taken in the measurements of the impedance. The pellet surfaces were covered with silver pastes electrodes whereas the platinum wires linked to the electrodes were used as current collectors.

\subsection{Theoretical studies}

To confirm the arrangement of the hydrogen bonds and the inter and intra-molecular interactions in our material, we studied it by Hirshfeld surfaces analysis, this is an excellent approach used to generate unit cell packing diagrams of the compounds. This analysis is based on a $3 \mathrm{D}$ graph that represents the space region where the molecules come in contact and another 2D that summarizes the complexes information contained in a structure and makes it possible to identify each type of interaction. The analysis and calculations of this empirical method were carried out using the Crystal Explorer version 3.1 [15] software imported on a CIF file.

The theoretical calculations have been performed by using the hybrid B3LYP/6-311++G (d,p) method implanted in the Gaussian 09 software package [16]. The GaussView 06 was used as molecular visualization program [17]. Due to the anharmonicity effect, the calculated vibrational frequencies were scaled by using a scaling factor. In our study a factor 0.958 in the range of wavenumbers above $1700 \mathrm{~cm}^{-1}$ were scaled by 0.958 whereas the range of wavenumbers below $1700 \mathrm{~cm}^{-1}$ were scaled by a factor equal to 0.983 [18, 19]. The assignments of the bands observed in both spectrum ( IR and Raman) were performed with 
the help of the corresponding TEDs using the VEDA4 package [20]. The GaussView package was used to verify the assignments of the bands. In this work, NBO calculations [21] were employed to calculate the donor-acceptor energy interactions, topological properties were determined with the AIM2000 program [22] in harmony with the Bader's theory [23].

\subsection{Chemical preparation of $\left(\mathrm{C}_{8} \mathrm{H}_{12} \mathrm{~N}\right) \mathrm{NO}_{3}$}

$\left(\mathrm{C}_{8} \mathrm{H}_{12} \mathrm{~N}\right) \mathrm{NO}_{3}$ was synthesized according to the following procedure. A solution containing $1 \mathrm{mmol}$ of nitritic acid $\left(\mathrm{HNO}_{3}\right)$ in $10 \mathrm{~mL}$ of distilled water was added to $1 \mathrm{mmol}$ of phenylethylamine in $10 \mathrm{~mL}$ of ethanol. The mixture was stirred at room temperature for one hour and then left to evaporate. After a few days of evaporation, the solution reaches saturation and gives rise to colorless crystals having a prismatic shape, stable and of suitable size for a structural study. Schematically the equation of the reaction can be written as follow:

$$
\mathrm{C}_{8} \mathrm{H}_{11} \mathrm{~N}+\mathrm{HNO}_{3} \longrightarrow\left[\mathrm{C}_{8} \mathrm{H}_{12} \mathrm{~N}\right]\left(\mathrm{NO}_{3}\right)
$$

\section{Results and discussion}

\subsection{X-ray diffraction and geometric optimization}

The unit formula of the title material (PEAN) (Fig. 1a) demonstrates a monoprotonated organic cation which is an inorganic anion $\left(\mathrm{NO}_{3}{ }^{-}\right)$and 2-phenethylammonium. The optimized geometry model of this compound is illustrated in Fig. 1b. To describe the atomic arrangement of our crystal structure, we have projected it along the $\overrightarrow{\boldsymbol{a}}$ axis (Fig. 2a). This projection shows the arrangement of $\mathrm{NO}_{3}{ }^{-}$anions in a corrugated manner in the $\mathrm{y}=1 / 4$ and $3 / 4$ positions between which the 2-phenylethylammonium groups are interleaved, which are interconnected by $\mathrm{C}-\mathrm{H} \ldots \pi$ interactions $[24,25]$, thus forming a cationic chains along the axis $\overrightarrow{\boldsymbol{c}}$ to $\mathrm{y}=0$ and $1 / 2$. These anionic and cationic groups are interconnected via weak hydrogen bonds $\mathrm{N}-\mathrm{H}$... $\mathrm{O}$. The hydrogen bonding strength can be interpreted according to Brown and Blessing criteria $[26,27]$ based on the donor-acceptor distance $(\mathrm{d}>2.73 \AA$ : weak; $\mathrm{d}<2.73 \AA$ : strong). Thus, in PEAN, there are three $\mathrm{N}-\mathrm{H} \ldots$... O hydrogen bonds, two to three centers (bifurcated) generating cycles $\boldsymbol{R}_{\mathbf{1}}^{2}(\mathbf{4})$ [28] and one at two centers (Table. 2). These bonds are considered to be weak according to the donor-acceptor distances which vary between 2.815 (2) and 3.254 (2) A. Each organic moiety is bonded to three different nitrate anions through five hydrogen bonds, thus forming $\boldsymbol{R}_{\mathbf{6}}^{\mathbf{4}}(\mathbf{1 4})$ and $\boldsymbol{R}_{\mathbf{1}}^{\mathbf{2}}(\mathbf{4})$ units [28] (Fig. 2b). The interatomic distances and the bonding angles of $\left(\mathrm{NO}_{3}{ }^{-}\right)$collected in Table 3 do not show any particularity compared to those generally encountered in nitrates known until now [29, 30]. Concerning the organic cation, the geometric characteristics classified in Table 3 are comparable to those observed for the same cation crystallizing with other types of anions [31]. The $\mathrm{C}-\mathrm{NH}_{3}{ }^{+}$bond 
length (1.48 (2) $\AA$ ) of the ammonium group is considerably higher than the $\mathrm{C}-\mathrm{NH}_{2}$ bond of the amine, this being explained by the protonation of 2-phenylethylamine. The benzene ring of the 2-phenethylammonium cation is perfectly plane, the mean deviation from its mean plane is $\pm 0.0019 \AA$ A. Packing of organic cations in the crystalline stack is ensured via $\mathrm{C}-\mathrm{H}$... $\pi$ interactions (Fig. 2c) with donor-acceptor distances (C...Cg) ranging from 3.554 (2) to 3.704 (2) $\AA$ (Table 2).

The geometric parameters studied experimentally by X-ray diffraction, and theoretically by BLYP methods with $311++\mathrm{G}(\mathrm{d}, \mathrm{p})$ and $311++\mathrm{G}(3 \mathrm{df}, 3 \mathrm{pd})$ basis, such as the bond lengths and the angles of the PEAN are tabulated in Table 3. Optimized molecular structure has a dipolar moment equal to 6.0203 Debye and energy worth -647.33030001 a.u. Protonation on the nitrogen atoms $\mathrm{N} 2$ of the cation and the loss of a proton of nitric acid are confirmed by the extension of $\mathrm{C} 1-\mathrm{N} 2, \mathrm{O} 2-\mathrm{N} 1$ and $\mathrm{O} 1-\mathrm{N} 1$ bonds respectively. These differences lead to the conversion of neutral state to ionic state. The C-C linkages in the phenyl of the 2phenylethylammonium group were calculated at the range of $1.3899 \AA-1.3993 \AA$, while the C-C-C binding angles were calculated between $118.3939^{\circ}$ and $120.94^{\circ}$. These values do not differ greatly from those observed by X-ray diffraction, which allows us to conclude that the aromatic nucleus is somewhat irregular. The average value of the calculated bond length of $\mathrm{C}-\mathrm{H}$ and $\mathrm{N}-\mathrm{H}$ is equal to 1.11 and elongated by about $0.1 \AA$ relative to the mean value observed by experimentally of 1.01. This later is due to the difference between the theoretical calculations which done to an isolated molecule in gaseous phase and experimental results which molecules is in solid state, where the crystal structure is related to intra and intermolecular interactions, such as van der Waals and hydrogen bonding interactions. The synergy between the organic group and the nitrate anion is carried out through hydrogen atom $\mathrm{H} 2 \mathrm{~N}$ which provide an intermolecular interaction between the two entities playing a very important role in the maintenance and the cohesion of the crystalline edifice. The angle of the intermolecular is correlated to be linear in both experimental and computational methods. Also the remarkable variation of $\mathrm{O} 3 \ldots \mathrm{H} 2 \mathrm{~N}$ distance experimentally compared with the results observed theoretically. This one suggests the importance and the strong character of the hydrogen bond N2-H2N ... O3.

\subsection{D cartographies and $2 D$ fingerprint plots}

The analysis of the three-dimensional graphic representation in $\boldsymbol{d}_{\text {norm }}$ illustrated in (Fig. 3a) makes it possible to identify the contacts which take place in our structure, namely the close contacts indicated by the red spots taking place between the hydrogen and oxygen atoms $(\mathrm{H}$... $\mathrm{O} / \mathrm{O} \ldots \mathrm{H}$ ) which are attributed to hydrogen bonds $\mathrm{N}-\mathrm{H} \ldots \mathrm{O}$. On the other hand, the large red 
spot on the aromatic nucleus and the blue spot surrounding the H1A and $\mathrm{H} 2 \mathrm{~B}$ hydrogen observed on the Shape index cartography (Fig. 3b), the large flat region delimited by a blue outline observed on the Curvedness graph (Fig. 3c), and the important contribution of the contacts $\mathrm{C} \ldots \mathrm{H} / \mathrm{H} \ldots \mathrm{C}(17.3 \%)$ on the Hirshfeld surface (Fig. 4d) are compatible with the presence of $\mathbf{C}-\mathbf{H} \ldots \boldsymbol{\pi}$ interactions in our structure. Noting the absence of the red and blue triangles on the Shape index cartography, the low contribution of the contacts C ... C $(0.8 \%)$ (Fig. 4e) thus the sum $\left(d_{i}+d_{e} \sim 3.6 \AA\right)$ greater than the sum of the van der Waals radii of the carbon atoms (3.4 $\AA$ ) confirm the absence of $\boldsymbol{\pi}-\boldsymbol{\pi}$ interactions in the crystalline stack. The full fingerprint plot and the fingerprints plots of the main contacts involved in the PEAN compound are illustrated in Fig. 4. At each point of the Hirshfeld surface is associated a $d_{e}$ and $d_{i}$ value. For a pair $\left(d_{i}, d_{e}\right)$, the sum of these components is equal to the distance separating the atoms contributing to this point. There are close contacts when the sum of these components is smaller or equal to the sum of the van der Waals rays of the involved atoms. Fig. 4b is a simplified illustration 2D that takes into account only the contacts between hydrogen and oxygen atoms, this graph reveal that these contacts occupy the largest space on the Hirshfeld surface (38.8\%) and appear as two narrow symmetric points located around a sum $\left(d_{e}+d_{i}=1.9 \AA\right)$ less than the sum of the van der Waals radii of the oxygen (1.52 $\left.\AA\right)$ and hydrogen $(1.09 \AA)$ atoms. These contacts clearly demonstrate the formation of hydrogen bonds $\mathrm{N}-\mathrm{H}$... O. The graph depicted in Fig. 4c represents the relationship between the hydrogen atoms $(\mathrm{H} \ldots \mathrm{H})$ which comprise $36.9 \%$ of the total surface area of Hirshfeld. It is observed for its contacts that a single quantity of pairs $\left(d_{e}, d_{i}\right)$ of high density located in the zone centered on the point $\left(d_{i}=1.1 \AA, d_{e}=1.1 \AA\right.$ ) use of color green. This value is almost equal to the van der Waals radii value of the hydrogen atom (1.09 $\AA$ ).

\subsection{AIM topological, reduced density gradient (RDG) and isosurface analyses}

R. Bader proposed an AIM topological approach [23, 32] which considers the electronic density $\rho(r)$ as a local function of the molecular system. This approach is a model which characterizes the chemical bonding of a system based on the topology of the charge density in the space $\rho(r)$. The AIM quantum theory allows characterizing the nature of interatomic interaction between two atoms involved, the non-binding interactions, the electronic structure and the chemical reactivity of molecule, from different topological properties $\left(\rho, \lambda_{i}(1,2,3)\right.$, $\nabla^{2} \rho(r)$ ), energy (the kinetic energy densities $G$, potential $V$ and total $H=G+V$ ) and the electronic distribution. Recall that the Laplacian of electronic density, defined as the sum of the three eigenvalues of Hessian matrix, given a valuable information on the charge 
concentration $\left(\nabla^{2} \rho>0\right.$ : depletion of load, $\nabla^{2} \rho<0$ : load concentration areas). The ellipticity $\varepsilon=\left|\frac{\lambda_{1}}{\lambda_{2}}\right|-1$, given also an idea of the accumulation (depletion) of charges in a given plane. According to AIM theory, a bond is characterized by the existence of a BCP (critical point of binding). In this context, the properties of BCP are analyzed according to the parameters described above. To calculate the properties of the bonds in our compound, in particular the hydrogen bonds Koch and Popelier [33] proposed three criteria to show the existence of a hydrogen bond:

- The presence of a BCP between the acceptor group and the hydrogen atom of the donor group confirms the existence of a hydrogen bond.

- The value of $\rho(\mathrm{BCP})$ at the BCP point should be low and located in the range $0.0020-0.0400$ a.u.

- The value of $\nabla^{2} \rho(\mathrm{BCP})$ should be positive and located in the domain $0.0240-0.1390$ a.u.

Based on the Rozas and al [34] criterion we have classified into three categories the hydrogen bonds:

- Weak hydrogen Bonds: $\nabla^{2} \rho\left(\mathrm{r}_{\mathrm{BCP}}\right)>0$ and $\mathrm{H}\left(\mathrm{r}_{\mathrm{BCP}}\right)>0$

- Moderate hydrogen bonds: $\nabla^{2} \rho\left(\mathrm{r}_{\mathrm{BCP}}\right)>0$ and $\mathrm{H}\left(\mathrm{r}_{\mathrm{BCP}}\right)<0$

- Strong or very strong hydrogen bonds: $\nabla^{2} \rho\left(\mathrm{r}_{\mathrm{BCP}}\right)<0$ and $\mathrm{H}\left(\mathrm{r}_{\mathrm{BCP}}\right)<0$

The graphical representation of AIM analysis of the PEAN compound is illustrate in Fig. 5. whereas the calculated topological parameters are listed in Table 4.

The AIM topological analysis reveals that our crystal is stabilized by three hydrogen bonds $\mathrm{O} 1 \ldots \mathrm{H} 1, \mathrm{O} 1 \ldots \mathrm{H} 2$ and $\mathrm{O} 2 \ldots \mathrm{H}$. According to the BCP analysis of Table 4, O1 ... H1 and $\mathrm{O} 1$ ... H2 are considered weak with hydrogen bond energies of -1.18171 and $-1.03322 \mathrm{kcal} / \mathrm{mol}$, the strength of these two hydrogen bonds is also confirmed by the Laplacian of electron density $(0.02270,0.01860)$ and the energy density $(0.60600,0.43177)$ with values greater than zero follow the Rozas criterion. Concerning the bond $\mathrm{O} 2 \ldots \mathrm{H}$, this bond has an energy $\mathrm{E}_{\mathrm{int}}=-8.97874 \mathrm{kcal} / \mathrm{mol}$, a Laplacian of the electronic density $\nabla^{2} \rho(\mathrm{r})=0.08946>0$ and an electronic density $\mathrm{G}(\mathrm{r})+\mathrm{V}(\mathrm{r})=-1.93379<0$, indicating that $\mathrm{O} 2 \ldots \mathrm{H}$ is a mean hydrogen bond. Positive Laplacian values indicate electronic charge depletion along the path of its links. The AIM confirms the presence of the H ... H contacts already observed by Hirshfeld surface analysis, so the existence of its intermolecular interactions is also a proof of the critical points $\mathrm{BCP}$. In addition, the presence of a new ring critical point ' $\mathrm{RCP}$ ' confirms the cyclic character of an atomic chain. As shown in Fig. 5, the interactions between the organic group and the nitrate anion via hydrogen bonds give rise to the formation of the rings NRCP1 
and NRCP2. The very low value of ellipticity $(\varepsilon=-1.2073)$ at the RCP point confirms that there is delocalization of electron in aromatic nucleus. Indeed the overall ellipticity suggests that there is a strong delocalization in PEAN crystalline structure $[\varepsilon(\mathrm{NRCP} 1)=-$ $1.8530, \varepsilon(\mathrm{NRCP} 2)=-1.7866]$. Electron localization function (ELF), local information entropy, reduced density gradient (RDG), localized orbital locator (LOL), average local ionization energy, ellipticity $(\varepsilon)$ and the eta index $(\zeta)$ of the hydrogen bonds in the PEAN material at the critical points BCP are detailed in Table 4.

The existing intermolecular interactions in PEAN compound experimentally processed by X-ray diffraction and confirmed theoretically by Hirshfeld surface analysis, geometric optimization and by AIM topological analysis, have been also validated and evaluated using the multi-wavefunction analysis, this latter was carried out by a RDG plot analysis and isosurface of interactions. The RDG approach is a dimensionless elementary amount obtained from the density and its first derivative developed by Johnson et al. [35]

$$
R D G(r)=\frac{1|\nabla \rho(r)|}{2\left(3 \pi^{2}\right)^{1 / 3} \rho(r)^{4 / 3}}
$$

Based on the density $\rho(\mathrm{r})$ against sign $\lambda_{2}$ we have tried to understand and indicate the nature of strength of the different interactions existing in our crystalline structure:

- If $\lambda_{2}<0$ : Attractive and binding interactions (hydrogen bonds).

- If $\lambda_{2}>0$ : repulsive and non-binding interactions (steric effect in ring and cage).

- Values close to zero indicating van der Waals interactions.

The results were performed and plotted respectively by the use of Multiwfn and VMD programs [36, 37]. These results were collected in Figs. 6a and 6b. Fig. 6a illustrates the attractive, van der Waals and repulsive interactions in the PEAN structure. These interactions appear as zones marked respectively by blue, green and red circles. Turning to Fig. 6b, a clear blue spot is cheked between the hydrogen and oxygen atoms, which signify the strong attractive interaction N-H ... O. The interactions appear in the form of green plates are attributed to van der Waals interactions; its plates are located exactly between the hydrogen atoms. The elliptic red plate located at the center of the aromatic nucleus is related to repulsive interactions which show a strong steric effect. 


\subsection{Natural Bond order analysis}

Natural bond analysis (NBO) is an powerful method that allows us to study and identify the specific bonds and energies associated with one-pair electrons, which play a very important and essential role in physico-chemical processes [38, 39]. This method has been used to establish electronic exchanges, transfer reactions, hydrogen bonding between donoracceptor compounds and hyperconjugative interactions. The difference of energy between interacting orbitals give an idea for the interaction force between acceptor electrons and donor electrons or otherwise the stability of the orbital interactions. The most stable interaction can be estimated by calculating the second-order stabilization energy $\mathrm{E}^{(2)}[40]$ :

$$
E^{(2)}=q_{i} \frac{F^{2}(i, j)}{\varepsilon_{i}-\varepsilon_{j}}
$$

Where $\mathrm{q}_{\mathrm{i}}$ is the occupation of $\mathrm{i}$ orbital, $\varepsilon_{i}$ and $\varepsilon_{j}$ are the diagonal elements of orbital energies $\mathrm{i}$ and $j$ and $F(i, j)$ is the Fock matrix element outside diagonal. The value of $E^{(2)}$ energy is directly related to the intensity of interaction between donor and electron acceptor, more $\mathrm{E}^{(2)}$ is large more the interaction between donor and electrons acceptor is intense.

The computed results are collated in Table 5. The examination of this table shows clearly the existence of a hydrogen bond $\mathrm{N}-\mathrm{H} \ldots \mathrm{O}$.This is explained by the important interactions between the free pair of $\mathrm{LP}(\mathrm{O} 3)$ and $\mathrm{LP}(\mathrm{O} 2)$ orbitals and the antibonding orbital $\pi^{*}(\mathrm{O} 1-\mathrm{N} 1)$ with stabilizing energies respectively equal to 47.66 and $55.1 \mathrm{kcal}^{\mathrm{mol}}{ }^{-1}$. The total stabilization energy of $\mathrm{LP}(\mathrm{O} 3) \rightarrow \sigma^{*}(\mathrm{~N} 2-\mathrm{H} 2 \mathrm{~N})$ interaction is14.04 kcal.mol-1 order. Interactions between the $\pi(\mathrm{C} 3-\mathrm{C} 4), \pi(\mathrm{C} 3-\mathrm{C} 4), \pi(\mathrm{C} 7-\mathrm{C} 8), \pi(\mathrm{C} 7-\mathrm{C} 8), \pi(\mathrm{C} 5-\mathrm{C} 6)$ and $\pi(\mathrm{C} 5-\mathrm{C} 6)$ bonding orbitals and antibonding orbitals $\pi^{*}(\mathrm{C} 7-\mathrm{C} 8), \pi^{*}(\mathrm{C} 5-\mathrm{C} 6), \pi^{*}(\mathrm{C} 3-\mathrm{C} 4), \pi^{*}(\mathrm{C} 5-\mathrm{C} 6)$, $\pi^{*}(\mathrm{C} 3-\mathrm{C} 4)$ and $\pi^{*}(\mathrm{C} 7-\mathrm{C} 8)$ lead to an average stabilization energy around $20.5 \mathrm{kcal}^{-\mathrm{mol}^{-1}}$. It is obvious that its interactions significantly affect the stabilization and consolidation of the crystalline architecture of PEAN compound.

\subsection{Molecular electrical potential surface and electron localization function}

The electrostatic potential surface is used to expect the behavior and the chemical reactivity of molecules. This property is a valuable tool for understanding molecular interactions. Its importance lies in the fact that it displays several molecular properties namely the regions of positive electrostatic potentials, negative and neutral in terms of a color code. The blue color indicates the positive values (region of strong attraction), the red indicates the negative values (region of strong repulsion) and the green indicates the neutral zone. The map of electrostatic potential surfaces of the PEAN compound is illustrate in Fig. 7a. These areas are plotted in the region between $-3.8 \mathrm{e}-2$ (red) and 3.8e-2 au (blue). The blue color reveals the 
strongest attraction whereas the red color indicates the strongest repulsion. The area of negative potentials (excess in electrons) are associated with the free doublets of oxygen atoms acceptor of $\mathrm{H}^{+}$proton of $\mathrm{NO}_{3}{ }^{-}$group while the regions of the positive potentials (deficient in electrons) are associated with the $-\mathrm{NH}_{3}{ }^{+}$group of the phenylethylammonium cation. This confirms the existence of intermolecular $\mathrm{N}-\mathrm{H} \cdots \mathrm{O}$ interactions. The electrophilic and nucleophilic sites explain the formation of the H-bonds between the nitrate and phenylethylammonium groups in the compound under study and its important role in its stabilization. The surface of the electrostatic potential is very useful in the search for a molecular structure with its physicochemical properties. A new map based on the critical points located inside this surface has been used in the Fig. 7b. Using the Monte Carlo method to calculate the values of the red and green spheres correspond respectively to the maximums and the minimums inside the surface, these data are collated in Table 6. The maximum energies located on this surface at the 6 th and 7 th green spheres as well as the minimum energies for the 3th and 4th blue spheres are derived from the interactions between the phenylethylamonium group and nitrate anion via N-H...O hydrogen bonds.

In quantum chemistry, the ELF is a measure of the possibility of discovering an electron in the locality of a reference electron density at a given point and with the same spin. The bifurcation diagram of the ELF localization domains generally gives information on the nature of the interactions by observing the order of domain separation (reduction process) when the value of ELF isosurface varies between 0 and 1. The ELF value close to 1 is relative to the maximum Pauli repulsion regions, while the minimum Pauli repulsion regions have the ELF value near 0. Fig. 8 clearly shows the topology of ELF function for the PEAN crystal. The red colored field located in the range $(0.8-1.0)$ is assigned to the high ELF values. The zone between 0.8 and 0.5 (yellow to green) corresponds to the average ELF values. Finally the series goes down from 0.5 to 0 represented by the blue color shows low ELF values. In conclusion we find that the red regions surrounded by hydrogen atoms with a single electron are the strongest with a maximum Pauli repulsion, while the other blue areas occupied by the nitrogen atom of nitrate group and the $\mathrm{C} 3$ and $\mathrm{C} 6$ atoms of organic cation having similar spin electrons close with a minimum Pauli repulsion.

\subsection{Vibrational IR spectra and assignments}

Work perform on nitrates $[41,42]$ allowed us on the one hand to distinguish the four domains of modes relating to valence vibrations and their separation of deformation modes on the other hand. The plane trigonal $\mathrm{NO}_{3}{ }^{-}$anion contains 4 atoms so it presents $(4 \times 3)-6=6$ 
vibrations modes. These six modes are decomposed according to a symmetrical elongation mode ( $v_{1}, A_{1}^{\prime}$, Raman), a symmetrical deformation mode $\left(v_{2}, A_{2}^{\prime}\right.$, IR), a doubly degenerated asymmetric elongation mode $\left(v_{3}, E\right.$ ', IR et Raman) and a doubly degenerate asymmetric deformation mode ( $v_{4}, E$ ', IR et Raman). The application of the correlation method between the free ion groups (D3h), the site group $\left(\mathrm{C}_{1}\right)$ and the factor group $\left(\mathrm{C}^{5}{ }_{2 \mathrm{~h}}\right)$ of (PEAN) crystal, generates 24 internal vibration modes divided into two groups according to their activities, 12 modes active in Raman and 12 active in IR. The calculated and the experimental IR spectra of PEAN compound were found in the region $450-4000 \mathrm{~cm}^{-1}$ are presented graphically and listed respectively in Fig. 9 and Table 7.

\section{Vibrational modes of the anion $\mathrm{NO}_{3}^{-}$}

Based on the work reported above we have estimated the vibration domain of the nitrate group which is located between 700 and $1400 \mathrm{~cm}^{-1}$. The intense bands around 1392 , 1349 and 1311 are attributed to the asymmetry stretching modes $v_{3}\left(\mathrm{NO}_{3}{ }^{-}\right)$, While the corresponding computed values are 1699, 1456 and $1269 \mathrm{~cm}^{-1}$. Another stretching vibration of $\mathrm{NO}_{3}^{-}$but symmetrical is provided at $1156 / 1031$ and $1266 / 924 \mathrm{~cm}^{-1}$ respectively experimentally and by the DFT method. The band which is located experimentally towards $820 \mathrm{~cm}^{-1}$ is related to the outside plane deformation mode of $\mathrm{NO}_{3}$ group, this mode it is theoretically calculated at $772 \mathrm{~cm}^{-1}$. Finally the absorptions at 696 and $603 \mathrm{~cm}^{-1}$ are related to the deformation modes in the plane; these values are in good agreement with the calculated value (667 and $\left.640 \mathrm{~cm}^{-1}\right)$.

\section{Vibration modes of $-\mathrm{NH}_{3}^{+}$}

The $-\mathrm{NH}_{3}{ }^{+}$groups of phenyethylammonium cation react with the nitrate anions via the $\mathrm{N}-\mathrm{H}$ ... O type hydrogen bonds. The frequency of the band resulting from this type of coupling is observed experimentally at $2509 \mathrm{~cm}^{-1}$ and its theoretical peak located around $2428 \mathrm{~cm}^{-1}$. Generally $\mathrm{NH}_{3}{ }^{+}$stretching vibrations occur in the spectral range [3500-3000 $\left.\mathrm{cm}^{-1}\right]$ [43]. This is already confirmed by the experiment and by the DFT method where the bands correspond to asymmetric stretching vibrations $-\mathrm{NH}_{3}{ }^{+}$located respectively roughly $3447 \mathrm{~cm}^{-1}$ (experimentally) and $3492 \mathrm{~cm}^{-1}$ (theoretically). While the other symmetrical ones appear experimentally at $3385 \mathrm{~cm}^{-1}$ and theoretically to $3421 \mathrm{~cm}^{-1}$. Concerning the bending modes, the $\delta_{\text {as }}\left(\mathrm{NH}_{3}\right)$ bands are observed around 1640 and $1553 \mathrm{~cm}^{-1}$, these modes are calculated at 1577 $\mathrm{cm}^{-1}$. While the $\delta_{\mathrm{s}}\left(\mathrm{NH}_{3}\right)$ are located experimentally towards $1385,1348,1311,1156 \mathrm{~cm}^{-1}$ and the calculated at 1357, 1297 and $1114 \mathrm{~cm}^{-1}$.

\section{Vibration modes of $-\mathrm{CH}_{2}$ group}


The stretching modes of the $-\mathrm{CH}_{2}$ group (asymmetric and symmetric) generally appear at about 3100 and $3000 \mathrm{~cm}^{-1}$ [44]. The band observed at $3043 \mathrm{~cm}^{-1}$ in the infrared spectrum is a attached to the symmetric stretching of methylene group $\left(-\mathrm{CH}_{2}\right)$, the matching theoretical mode appears at $3034 \mathrm{~cm}^{-1}$. The asymmetric stretching modes of this group are computed at 3014, 2971 and $2963 \mathrm{~cm}^{-1}$ while the experimental modes are located at 3006 and $2963 \mathrm{~cm}^{-1}$. The deformation modes of the $-\mathrm{CH}_{2}$ groups are observed experimentally in the frequency region between 1553 and $1037 \mathrm{~cm}^{-1}$, and their calculated by the DFT method appears in the spectral domain range between 1575 and $1007 \mathrm{~cm}^{-1}$.

\section{Ring vibration}

The multiple weak bands in the frequency region $3100-3000 \mathrm{~cm}^{-1}$, in the aromatic compounds, are principal due to the $\mathrm{C}-\mathrm{H}$ stretching vibration in the aromatic cycle [45]. Absorptions observed at 3093, 3049 and $3018 \mathrm{~cm}^{-1}$ are attributed to $\mathrm{C}-\mathrm{H}$ stretching vibrations (computed at 3141,3129 and $3120 \mathrm{~cm}^{-1}$ ). Focusing on the $\mathrm{C}-\mathrm{H}$ in-plane bending vibrations, the frequencies of these vibrations are appear as medium strong to strong bands experimentally in the spectral range $1553-1037 \mathrm{~cm}^{-1}$. In theoretical FT IR spectrum these vibrations are limited between 1575 and $1007 \mathrm{~cm}^{-1}$. The stretching modes $v(\mathrm{C}-\mathrm{C})$ of the phenyl group are observed respectively around 1640,1547, 1392, 1348, 1311 $\mathrm{cm}^{-1}$. These vibrations are calculated at 1575, 1553, 1424, 1284 and $1173 \mathrm{~cm}^{-1}$. The aromatic carboncarbon $(\mathrm{C}=\mathrm{C})$ deformation vibration in the plane occurs experimentally in the region 1000 $490 \mathrm{~cm}^{-1}$ and calculated in the frequency region between $1007-492 \mathrm{~cm}^{-1}$. The peak around 485 $\mathrm{cm}^{-1}$, affected to the deformations out of the plane of $\mathrm{C}=\mathrm{C}$ groups. The same vibrations are calculated at about $492 \mathrm{~cm}^{-1}$.

\subsection{Thermal behavior}

To understand the behavior of the tile compound, thermal analysis DTA/TG (Fig.10a) of our compound carried out on a mass sample equal to $5.63 \mathrm{mg}$ in air with a heating rate of 5 $\mathrm{K} \cdot \mathrm{min}^{-1}$ in an alumina crucible from $0 \mathrm{~K}$ up to $850 \mathrm{~K}$ shows the existence of three endothermic peaks located respectively at 341,368 and $408 \mathrm{~K}$ on the DTA curve without a weight loss on the TG curve correspond to three successive phase transitions and an exothermic peak at $498 \mathrm{~K}$ accompanied by a significant weight loss $(82.50 \%)$, during which our product undergoes total combustion which leads to volatile gases and a black carbonaceous residue.

The calorimetric thermal analysis (Fig.10b) carried out on this compound $(\mathrm{m}=6.8 \mathrm{mg})$ in the temperature range between 298 and $573 \mathrm{~K}$ under an argon atmosphere and with a heating rate equal to $5 \mathrm{~K} \cdot \mathrm{min}^{-1}$ represents the same peaks corresponding to same phenomena 
previously observed by DTA. In the subject to study the properties of the phase transitions which appear at about 341, 368 and $408 \mathrm{~K}, 9.4 \mathrm{mg}$ of product are placed in an aluminum nacelle heated from $280 \mathrm{~K}$ to $428 \mathrm{~K}$ and then cooled to ambient temperature. The DSC curve (Fig. 11) shows during heating three endothermic peaks at 340,373 and $423 \mathrm{~K}$ and three exothermic peaks during cooling at 318,370 and $417 \mathrm{~K}$. These peaks suggest the detection of three successive reversible phase transitions.

\subsection{Electrical transport properties}

Research in the field of ionic conductivity and understanding the mechanism of shortrange interactions in materials has evolved very rapidly thanks to the explorer of many materials with a very high ionic conductivity, which is very important both in electronics field and in the energy field. From one material to another, the conductivity differs as well by the nature of responsible species for the conduction $\left(\mathrm{Li}^{+}, \mathrm{Na}^{+}, \mathrm{Ag}^{+}, \mathrm{H}^{+} \ldots\right)$ than by the temperature range of use and the dimensionality of conductive phase (3D, tunnel, lamellar...). In order to discover a possible electrical conduction in the synthesized organic nitrate (PEAN) we have undertaken a dielectric studies to better understand the properties of electric transport in this crystal as a temperature function and in a wide range of frequencies $(0.01-13000 \mathrm{kHz})$. The sample is presented in the pellet form of a $13 \mathrm{~mm}$ diameter obtained from polycrystalline powder compressed at a pressure of about 7 tons in a cylindrical stainless steel matrix attacking a thickness of $1.25 \mathrm{~mm}$. In the subject to find a uniform electric contact, a $\mathrm{Ag}$ lacquer is deposited on both sides of the pellet.

\section{Impedance spectroscopy}

We have chosen to represent the electrical response of the (PEAN) material by Nyquist diagram (Fig.12a). The representative points of the complex impedance $Z$ are arranged in an arc of approximately circular shape at the highest frequencies. The most important parameter for the subsequent study is the $\mathrm{R}$ resistance, whose value makes it possible to calculate the conductivity of (PEAN) material. To better describe the experimental Nyquist diagram, it therefore seems logical to model the electrical behavior by the series association of $\mathrm{R}$ and CPE cells, corresponding to the contributions of grains in the materials. In the circuit equivalent: $\mathrm{R}$ and $\mathrm{CPE}$ are the resistance and the constant phase element, respectivly, used to reimburse the non-homogeneity of the system. These spectra (Fig.12a), passing close to the origin, are constituted by semicircles centered below the real axis suggesting the leaving from ideal Debye behavior [46]. We represent at diverse temperatures, as a function of the frequency, the variation of the real part Z' and imaginary part Z' of the impedance. Indeed the Fig.12b $\left(Z^{\prime}=\mathrm{f}(\log f)\right)$ shows that $Z^{\prime}$ decreases during the temperature and frequency 
increasing, while we note in Fig.12c, which represents Z" = f $(\log )$ the appearance of peaks $\left(\omega_{\max }, Z{ }^{\prime}{ }_{\max }\right)$ whose increase in temperature causes a reduction in intensity. It is observed that everyone of these peak is centered at a maximum frequency $\left(f_{\max }\right)$ and when the temperature increase these peak shifts towards the high frequencies. This explains the dependence of the relaxation phenomenon with the temperature $[47,48]$ and the position of these peaks follows the condition $\omega_{\mathrm{m}} \cdot \tau_{\mathrm{m}}=1[47-49]$.

\section{$\underline{\text { Electrical conductivity }}$}

The knowledge of geometry of the sample (surface [S] and thickness [e]) makes it possible to calculate the conductivity $\sigma$ of the sample at a given temperature according to the equation:

$$
\sigma=\frac{\mathrm{e}}{\mathrm{SR}}
$$

Conductivity measurements being performed at different temperatures, it is then possible to plot the $\log (\sigma . \mathrm{T})=\mathrm{f}(1000 / \mathrm{T})$ curve for our sample (PEAN) (Fig.12d). These measurements revealed a slope break at $\mathrm{T}=378 \mathrm{~K}$, hence our representative curve consists of two regions, each region in the form of an affine branch that obeys the Arrhenius law:

$$
\sigma \mathrm{T}=\mathrm{A} \exp \left(-\mathrm{E}_{\mathrm{a}} / \mathrm{KT}\right)
$$

In the last equation $\mathrm{A}, \mathrm{K}$ and $\mathrm{E}_{\mathrm{a}}$ represent, respectively, the pre-exponential factor, the Boltzman constant and the activation energy.

Beyond the temperature $378 \mathrm{~K}$ the activation energy increases considerably and goes from $\mathrm{Ea}_{1}=0.08 \mathrm{eV}$ to $\mathrm{Ea}_{2}=0.2 \mathrm{eV}$. In the vicinity of this temperature a phase transition has been detected, this thermal phenomenon is already confirmed by DTA $(341 \mathrm{~K})$, TG and DSC up $(340 \mathrm{~K})$ and down $(318 \mathrm{~K})$ temperature. The abrupt change in conductivity marks the transition to a more chaotic state that could be correlated with the changes in the orientation of phenylethylammonium or $\mathrm{NO}_{3}$ - ions and the high dynamic disorder of the $-\mathrm{NH}_{3}{ }^{+}$groups in the hydrogen bonds $\mathrm{N}-\mathrm{H} \cdots$ O. For $\mathrm{Ea}_{2}=0.20 \mathrm{eV}$, the conductivity increases to a value equal to $1.21 .10^{-4} \Omega^{-1} \mathrm{~cm}^{-1}$, this important variation probably suggests the high mobility of $\mathrm{H}^{+}$ protons under the effect of thermal agitation, also the appearance of new charge dipole-dipole type carriers which improves the conductivity within our material.

\section{Correlation between electrical and structural properties}

The augmentation of the temperature has a very interesting effect on the architecture and the network of our crystal building, it favors the vibration of layers formed by the organic groups and the nitrate anions can lead to the rapid mobility of $\mathrm{H}^{+}$proton in the hydrogen bond network and to the reorientation of the ions $\mathrm{NO}_{3}{ }^{-}$. In addition, it's worth noting that the X-ray study shows that the H-bonding system in the PEAN compound is three-dimensional taking 
into account the interactions of type $\mathrm{C}-\mathrm{H} \ldots \pi$ which own a strong conductivity wherever the motion of the protons $\mathrm{H}^{+}$takes place in the 3D directions [50]. Besides, the conductivity in the studied structure is superior to those in the lamellar structures where the movement of $\mathrm{H}^{+}$ happens in only $2 \mathrm{D}[51]$.

\section{Conclusions}

Single crystals of a novel proton transfer compound phenylethylammonium trioxonitrate (PEAN) was crystallized at $300 \mathrm{~K}$ by slow evaporation-solution growth technique and investigated by X-ray diffraction, thermal analyses, IR spectroscopy and ionic conductivity in the solid state phase. XRD reveals the arrangement of $\mathrm{NO}_{3}{ }^{-}$anions in a corrugated behavior in the $\mathrm{y}=1 / 4$ and $3 / 4$ positions between which the 2-phenylethylammonium groups are interleaved, which are interconnected by $\mathrm{C}-\mathrm{H} \ldots \pi$ interactions. These latter interactions allow the reinforcement of the 3D network. The Hirshfeld surface study was used to evaluate the intermolecular contacts in the crystal arrangement namely $\mathrm{H} \ldots \mathrm{H}, \mathrm{H} \ldots \mathrm{O} / \mathrm{O} \ldots \mathrm{H}, \mathrm{C} . . . \mathrm{H} / \mathrm{H} \ldots \mathrm{C}$, C...C. The experimental vibrational frequencies of the fundamental modes of PEAN have been properly analyzed, assigned, and compared the theoretical results. NBO, AIM analysis has been used to study the stability of our compound. The thermal analyses show three successive phase transitions, one of them is confirmed by ionic conductivity. In addition a correlation between structural and electrical properties is also occurs. 


\section{Reference}

[1] L.M. Novena, S.S. Kumar, S. Athimoolam, Improved solubility and bioactivity of theophylline (a bronchodilator drug) through its new nitrate salt analysed by experimental and theoretical approaches, J. Mol. Struct. 1116 (2016) 45-55.

[2] A. Müller, F. Peters, M.T. Pope, D. Gatteschi, Polyoxometalates: very large clustersnanoscale magnets, Chem. Rev. 98 (1998) 239-272.

[3] P.V. Braun, P. Osenar, V. Tohver, S.B. Kennedy, S.I. Stupp, Nanostructure templating in inorganic solids with organic lyotropic liquid crystals, J. Am. Chem. Soc. 121 (1999) 7302-7309.

[4] Y. Li, Y. Yu, L. Wu, J. Zhi, Processable polyaniline/titania nanocomposites with good photocatalytic and conductivity properties prepared via peroxotitanium complex catalyzed emulsion polymerization approach, Appl. Surf. Sci. 273 (2013) 135-143.

[5] P. Englebienne, A.V. Hoonacker, Goldeconductive polymer nanoparticles: a hybrid material with enhanced photonic reactivity to environmental stimuli, J. Colloid Interface Sci. 292 (2) (2005) 445-454.

[6] H. C. Sabelli and J. I. Javaid, Phenylethylamine modulation of affect: therapeutic and diagnostic implications. J Neuropsychiatry Clin Neurosci, 1995. 7(1): p. 6-14.

[7] G. B. Baker, et al., Phenylethylaminergic mechanisms in attention-deficit disorder. Biol Psychiatry, 1991. 29(1): p. 15-22.

[8] A. Kusaga, Decreased beta-phenylethylamine in urine of children with attention deficit hyperactivity disorder and autistic disorder. No To Hattatsu, 2002. 34(3): p. 243-248.

[9] R. F.W. Bader, Atoms in Molecules, a Quantum Theory, Oxford University Press, Oxford, 1990. ISBN 0198558651.

[10] E. D. Glendening, J.K. Badenhoop, A.D. Reed, J.E. Carpenter, F. Weinhold, NBO 3.1, Theoretical Chemistry Institute, University of Wisconsin, Madison, WI, 1996.

[11] Bruker, APEX2, SAINT and SADABS, Bruker AXS Inc., Madison, Wisconsin, USA, 2006.

[12] A. Altomare, M.C. Burla, M. Camalli, G.L. Cascarano, C. Giacovazzo, A. Guagliardi, A. G. G. Moliterni, G. Polidori, R. Spagna, J. Appl. Cryst. 32 (1999) 115-119. 
[13] G.M. Sheldrick, Crystal structure refinement with SHELXL, Acta Cryst. C71 (2015) 3-8.

[14] L. J. Farrugia, WinGX and ORTEP for windows: an update, J. Appl. Cryst. 45 (2012) 849-854.

[15] S.K. Wolff, D.J. Grimwood, J.J. McKinnon, M.J. Turner, D. Jayatilaka, M.A. Spackman, CrystalExplorer 3.1, University of Western Australia, Crawley, Western Australia, 2013, 2005e2013, http://hirshfeldsurface.net/ CrystalExplorer.

[16] M.J. Frisch, et al., GAUSSIAN 09, Revision A.02, Gaussian, Inc., Wallingford, CT, 2009.

[17] R.I. Dennington, T. Keith, J. Millam, GaussView, Version 5.0.8, Semichem. Inc, Shawnee Mission, KS, 2008.

[18] M. Karabacak, A. Coruh, M. Kurt, FT-IR, FT-Raman, NMR spectra, and molecular structure investigation of 2,3-dibromo-N-methylmaleimide: a combined experimental and theoretical study, J. Mol. Struct. 892 (2008) 125-131.

[19] N. Sundaraganesan, S. Illakiamani, H. Saleem, P.M. Wojciechowski, D. Michalska, FT-Raman and FT-IR spectra, vibrational assignments and density functional studies of 5-bromo-2-nitropyridine, Spectrochim. Acta A Mol. Biomol. Spectrosc. 61 (2005) 2995-3001.

[20] M.H. Jamr_oz, Vibrational Energy Distribution Analysis, VEDA 4, Computer Program, Poland, 2004.

[21] E.D. Glendening, J.K. Badenhoop, A.D. Reed, J.E. Carpenter, F. Weinhold, NBO 3.1, Theoretical Chemistry Institute, University of Wisconsin, Madison, WI, Oxford, 1996, ISBN 0198558651, p. 1990.

[22] F. Biegler-K€oning, J. Sch€onbohm, D. Bayles, AIM2000; a program to analyze and visualize atoms in molecules, J. Comput. Chem. 22 (2001) 545.

[23] R.F.W. Bader, Atoms in Molecules. A Quantum Theory, Oxford University Press, Oxford, 1990, ISBN 0198558651.

[24] A. Elboulali, S. Akriche, S. Al-Deyab \& M. Rzaigui, Acta Cryst., E69, o213-o214, (2012).

[25] S. Durre, M. Nawaz, T. Naem, A. M. Khan \& A.Yasmeen, Acta Cryst., E65, o1312, (2009).

[26] Blessing, R. H. (1986). Acta Cryst. B42, 613-621.

[27] Brown, I. D. (1976). Acta Cryst. A32, 24-31. 
[28] Bernstein, J., David, R. E., Shimoni, L. \& Chang, N.-L. (1995). Angew. Chem. Int. Ed. Engl. 34, 1555-1573.

[29] S. Gatfaoui, N. Issaoui, A. Mezni, F. Bardak, T. Roisne, A. Atac, H. Marouani, Synthesis, structural and spectroscopic features, and investigation of bioactive nature of a novel organic-inorganic hybrid material 1H-1,2,4-triazole-4-ium trioxonitrate, J. of Mol. Struct. 1150 (2017) 242-257.

[30] S. Gatfaoui, N. Issaoui, Silvia A. Brandan,T. Roisnel, H. Marouani, Synthesis and characterization of p-xylylenediaminium bis(nitrate). Effects of the coordination modes of nitrate groups on their structural and vibrational properties, J. of Mol. Struct. 1151 (2018) 151-168.

[31] G. Hernández, S. Bernès, R. Portillo \& R. Gutiérrez, Acta Cryst., E63, o1053-o1055, (2007)

[32] F. Biegler-Köning, J. Schönbohm, D. Bayles, AIM2000; a program to analyze and visualize atoms in molecules, J. Comput. Chem. 22 (2001) 545.

[33] U. Koch, P. Popelier, J. Phys. Chem. A 99 (1995) 9747.

[34] I. Rozas, I. Alkorta, J. Elguero, Behavior of Ylides containing N, O, and C atoms as hydrogen bond acceptors, J. Am. Chem. Soc. 122 (2000) 11154-11161.

[35] E.R. Johnson, S. Keinan, P. Mori-Sánchez, J. Contreras-García, A.J. Cohen, W. Yang, J. Am. Chem. Soc. 132 (2010) 6498-6506.

[36] E. Runge, E.K.U. Gross, Phys. Rev. Lett. 52 (1984) 997-1000.

[37] W. Humphrey, A. Dalke, K. Schulten, J. Mol. Graph. 14 (1996) 33-38 27-38.

[38] V. Pophristic, L. Goodman, N. Guchhait, J. Phy. Chem. A., 101(1997) 4290-4297.

[39] F. Weinhold, Nature., 411(2001) 539-541

[40] F. Weinhold, C.R. Landis, Valency and Bonding: A Natural Bond Orbital DonorAcceptor Perspective, Cambridge University Press, Cambridge, 2005.

[41] L. Sobczyk, A. Pawlukoj_c, E. Grech, A. Huczy_nski, B. Brzezinski, Extremely different structures and vibrational spectra of tetramethylpyrazine nitrate dihydrate in solid and solutions, J. Mol. Struct. 1037 (2013) 264.

[42] D.J. Goebbert, E. Garand, T. Wende, R. Bergmann, G. Meijer, K.R. Asmis, D.M. Neumark, Infrared spectroscopy of the microhydrated nitrate ions NO3_(H2O)1_6, J. Phys. Chem. A 113 (2009) 7584.

[43] G. Socrates, Infrared Characteristic Group Frequencies, John Wiley and Sons,New York, (1980). 
[44] P. Srinivasan, M. Gunasekaran, T. Kanagasekaran, R. Gopalakrishnan, P. Ramasamy, 2,4,6-trinitrophenol (TNP): An organic material for nonlinear optical (NLO) applications J. Cryst. Growth 289 (2006) 639-646.

[45] G. Socrates, Infrared and Raman Characteristic Group Frequencies, third ed., Wiley, New York, 2001.

[46] J.R. Macdonald, Impedance spectroscopy, Ann. Biomed. Eng. 20 (1992) 289-305.

[47] M. F. Mostafa \& S. S. El-khiyami, J. Solid State Chem., 209, (2014), 82-88.

[48] H. Chouaib, \& S. Kamoun, J. Phys. Chem. Solids, 85, 218-225, (2015).

[49] R. Elwej, M. Hamdi, N. Hannachi, F. Hlel, Mater. Res. Bull. 62 (2015) 42-51.

[50] P. Hagenmuller, W. Van Gool, Solid Electrolytes, Academic Press, 1978, 195-213.

[51] H. Barbes, G. Mascherpa, R. Fourcade, B. Ducourant, J. Solid State Chem. 60 (1985) 95-100. 


\section{Figure Captions}

Fig.1: ORTEP drawing of (PEAN) with the atom-labeling scheme. Displacement ellipsoids are drawn at the $30 \%$ probability level. $\mathrm{H}$ atoms are represented as small spheres of arbitrary radii (a) and the optimized molecular structure (b).

Fig.2 : Projection along the $\vec{a}$ axis of atomic arrangement of PEAN (a). Hydrogen bond motifs in (PEAN) (b). Interactions between organic cations C-H... $\pi$ stacking (c).

Fig.3 : Hirshfeld surfaces mapped with $d_{\text {norm }}$ (a) (dotted lines "red" represent hydrogen bonds), shape index (b) and curvedness (c) for the PEAN.

Fig.4 :Fingerprint plots of the full and the import intercontacts and percentage of various intermolecular contacts contributed to the Hirshfeld surface in the PEAN compound.

Fig.5 : Graphical representation of the AIM analysis of PEAN: bond critical points (small red spheres), ring critical points (small yellow sphere), bond paths (pink lines).

Fig.6 : Reduced density gradient (a) and isosurface density (b) plot along with the color filled scale bar defining interaction limits for the PEAN compound.

Fig.7 : Molecular electrostatic potential MEP (a), Surfaces local minima and maxima of MEP are represented red and blue spheres of (PEAN).

Fig.8 : The map for electron density in the XY plane of PEAN. (For interpretation of the references to colour in this figure legend, the reader is referred to the web version of this article).

Fig.9 : Theoretical and experimental FT-IR spectrum of PEAN.

Fig.10 : DTA, TG (a) and DSC (b) curves c of (PEAN) at rising temperature.

Fig.11 : DSC curves rising and falling temperature of (PEAN).

Fig.12 : Cole-Cole plots (a), plots of the real and imaginary parts of impedance Z'(b) and Z',(c) vs $\log (\mathrm{f})$, Arrhenius plots ionic conductivity of $\operatorname{Ln}(\sigma . \mathrm{T})$ versus $1000 / \mathrm{T}$ of (PEAN) at various temperatures. 


\section{Tables captions}

Table 1 : Crystal data and experimental parameters used for the intensity data collection strategy and final results of the structure determination.

Table 2 : Hydrogen-bond geometry $\left(\AA,^{\circ}\right)$ of PEAN.

Table 3 : Bond length $\left(\mathrm{A}^{\circ}\right)$, bond angles $\left(^{\circ}\right)$ and torsional angles $\left(^{\circ}\right)$ by $\mathrm{X}$-ray data (with estimated standard deviation in parentheses) and by theoretical calculations at different levels of theory.

Table 4 : Topological parameters for Hydrogen bond interactions.

Table 5: Second order perturbation theory analysis of Fock matrix on NBO basis for the (PEAN) using B3LYP/ 6-311++G(d,p).

Table 6 : Analysis of molecular surface based on blue and red point numbers (Fig. 7).

Table 7: Observed and calculated wavenumbers $\left(\mathrm{cm}^{-1}\right)$ and assignments for (PEAN) compound. 


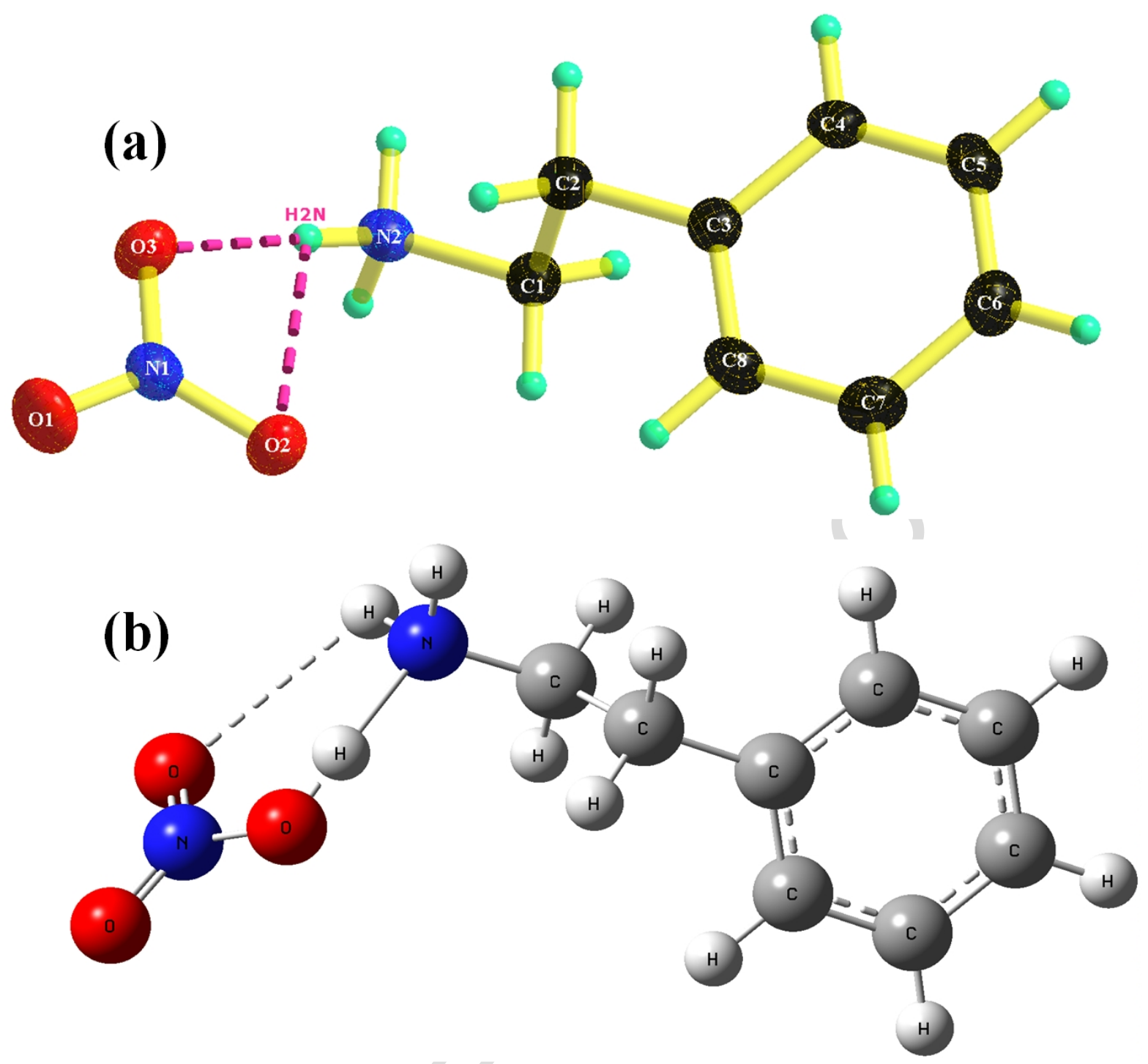

F ig . 1 
(a)

(b)

(c)

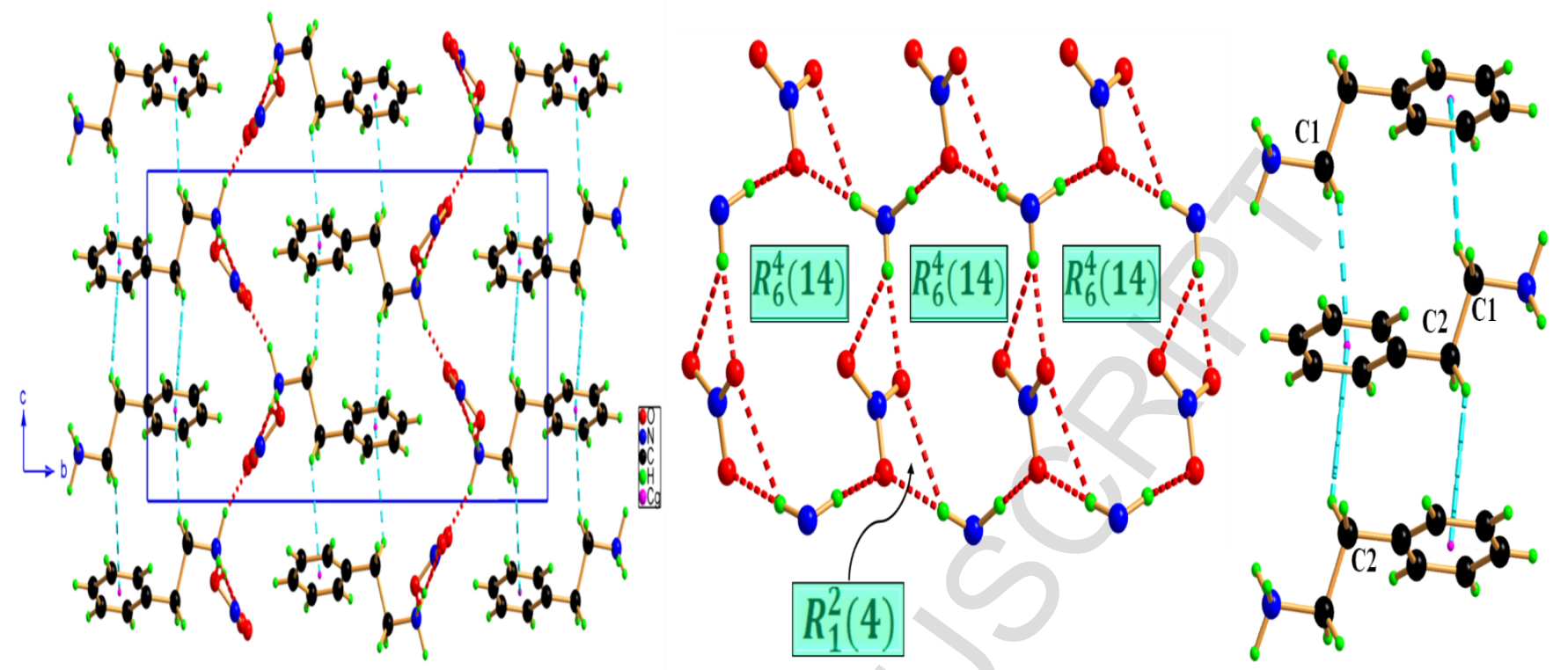

F i g . 2 
(a)

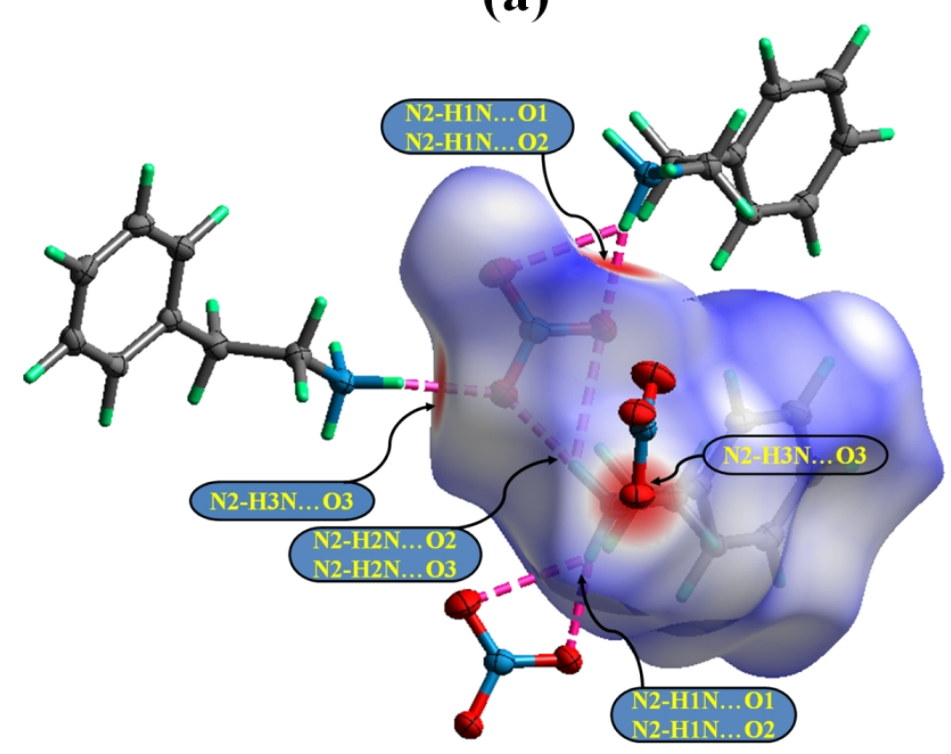

(b)

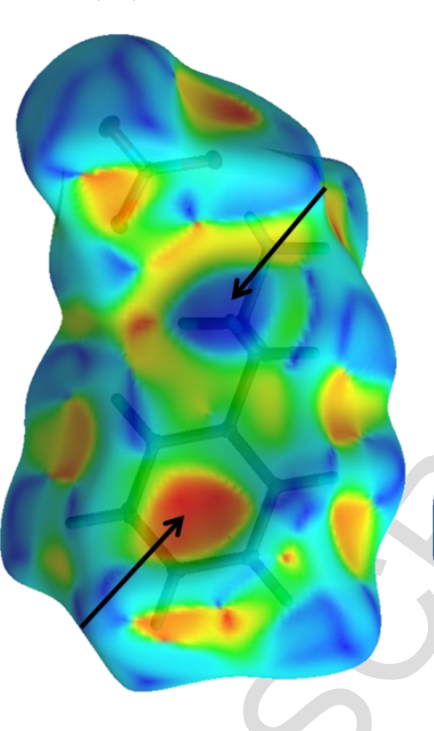

(c)

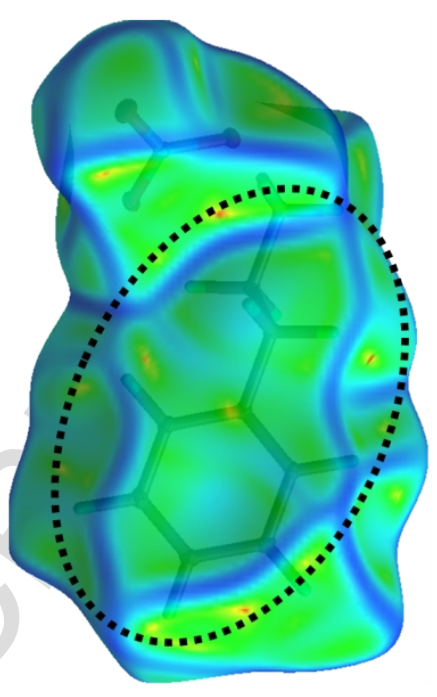

F i g . 3 

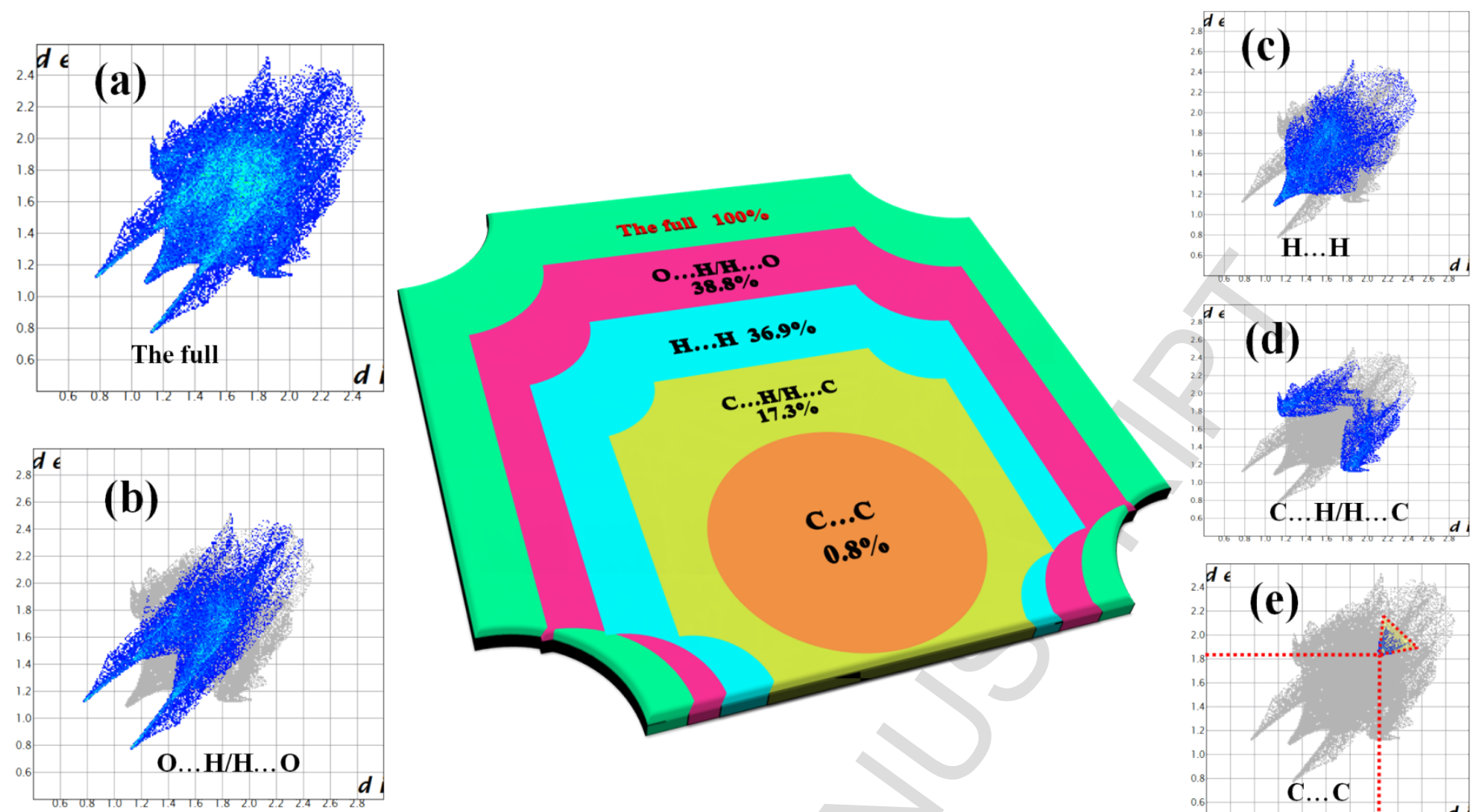

(d) C... $17 . .1 \%$

C...C $0.8 \%$

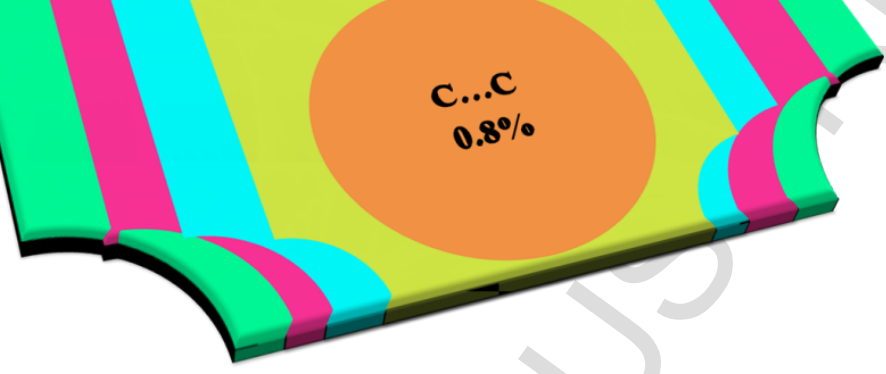

F i g . 4 


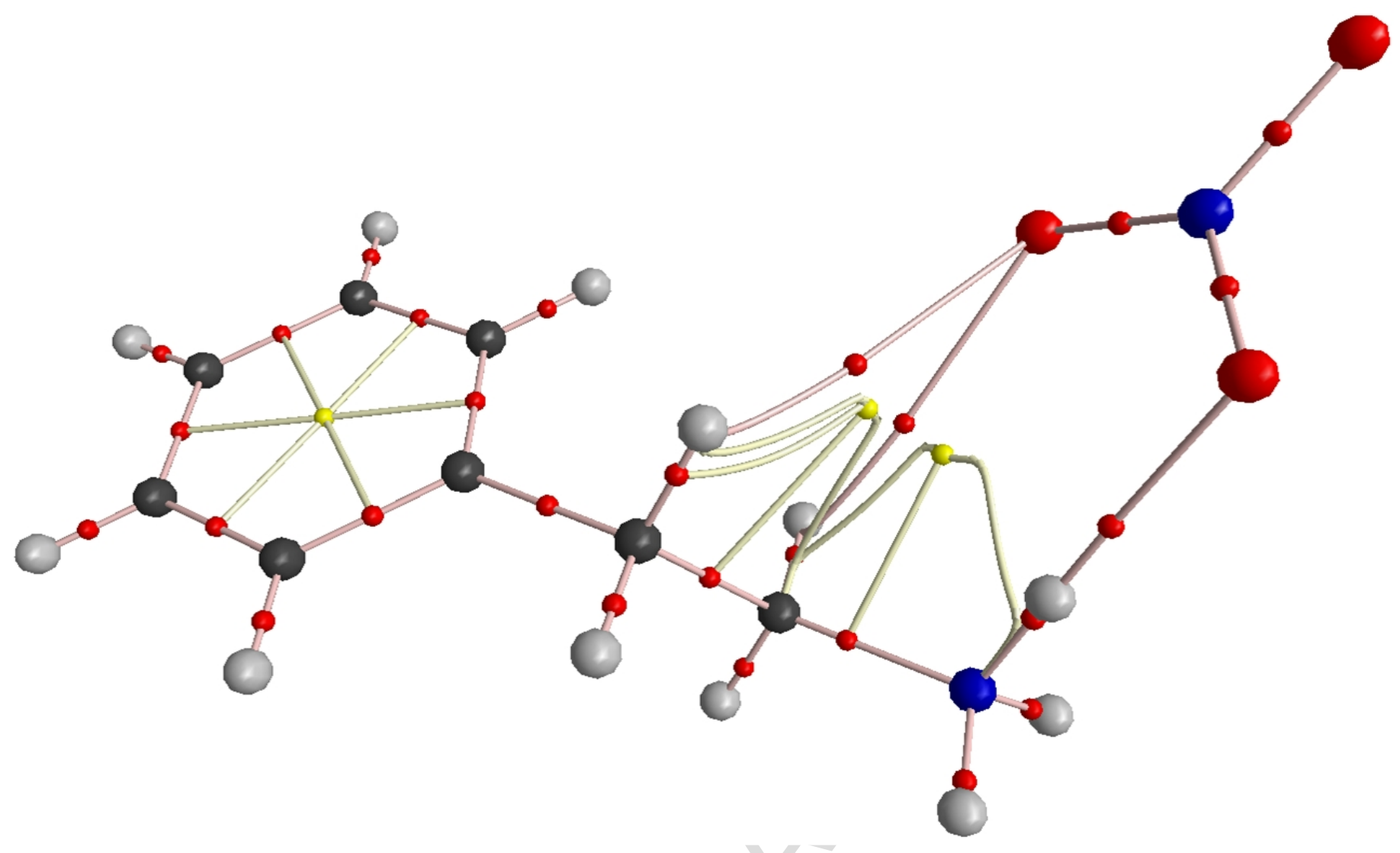

F i g . 5 
(a)

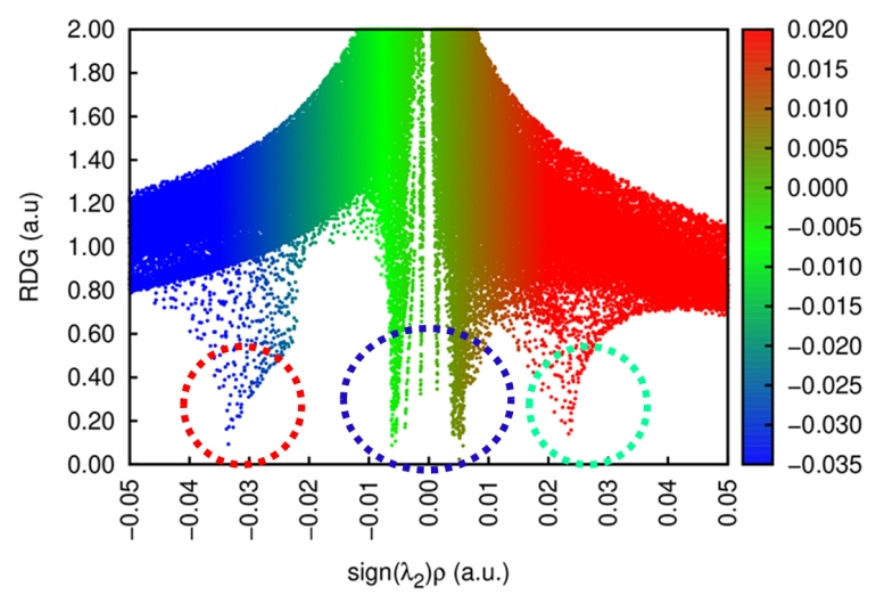

(b)

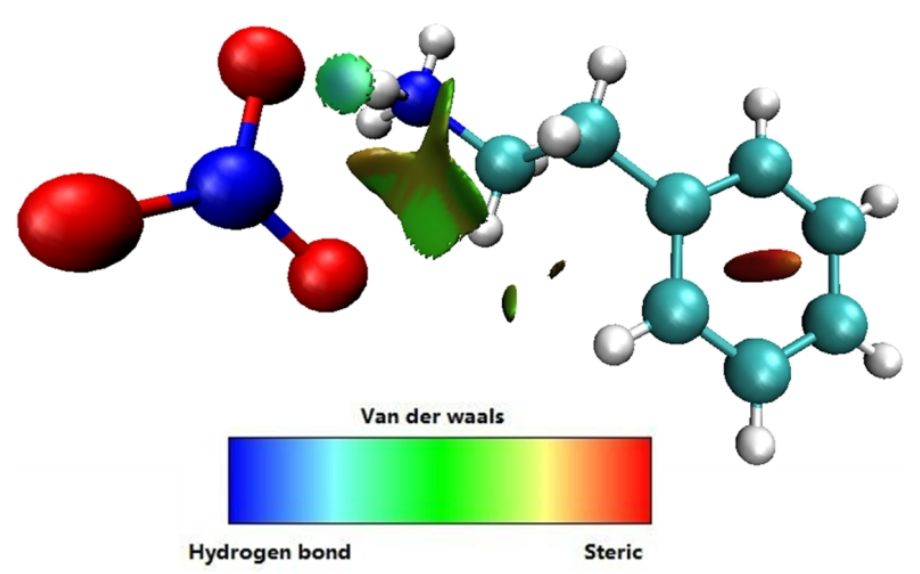

F i g . 6 


$$
-3.8 \mathrm{e}-2
$$

3.8e-2

(a)
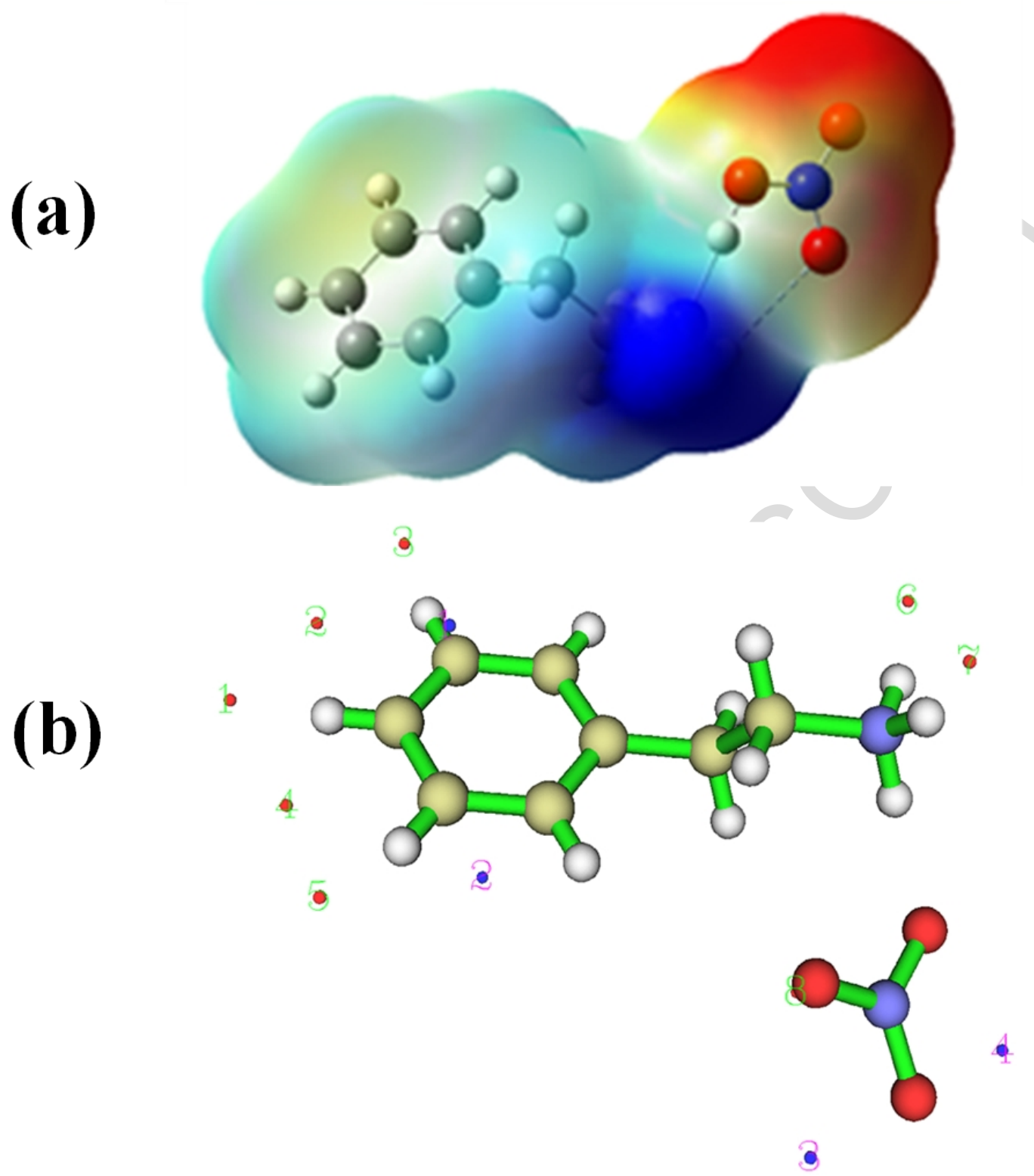

F i g . 7 

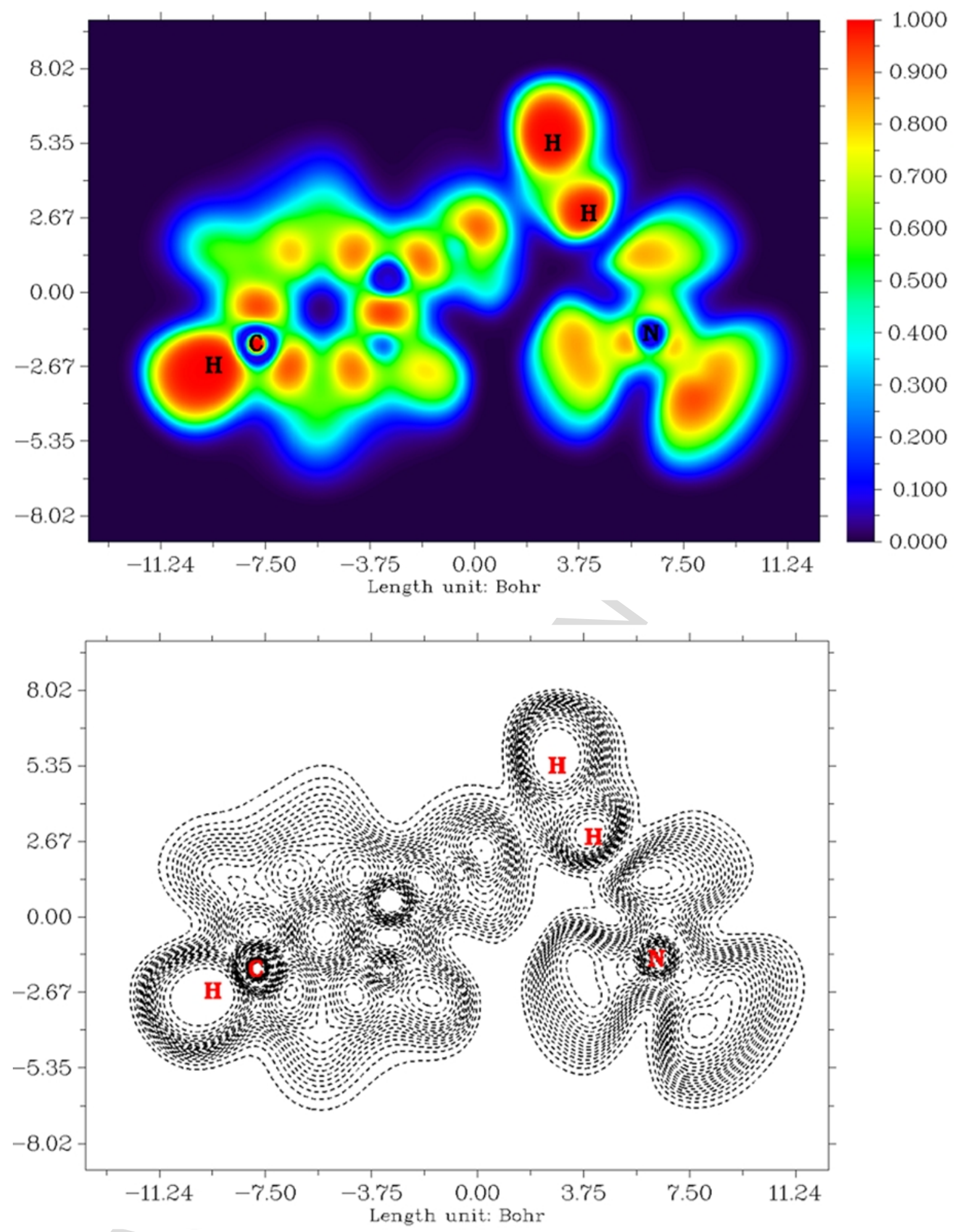

F i g . 8 


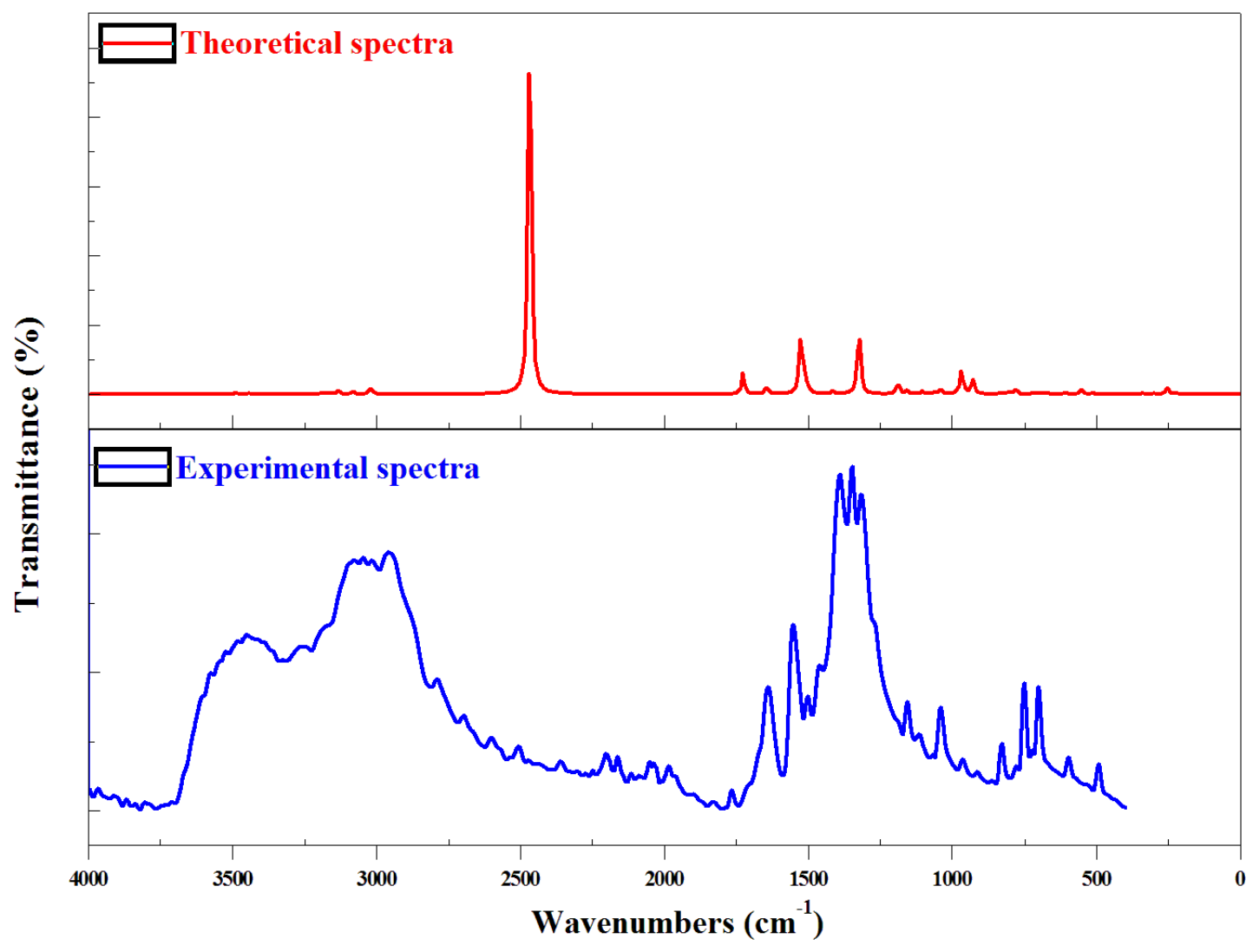

F i g . 9 
(a)

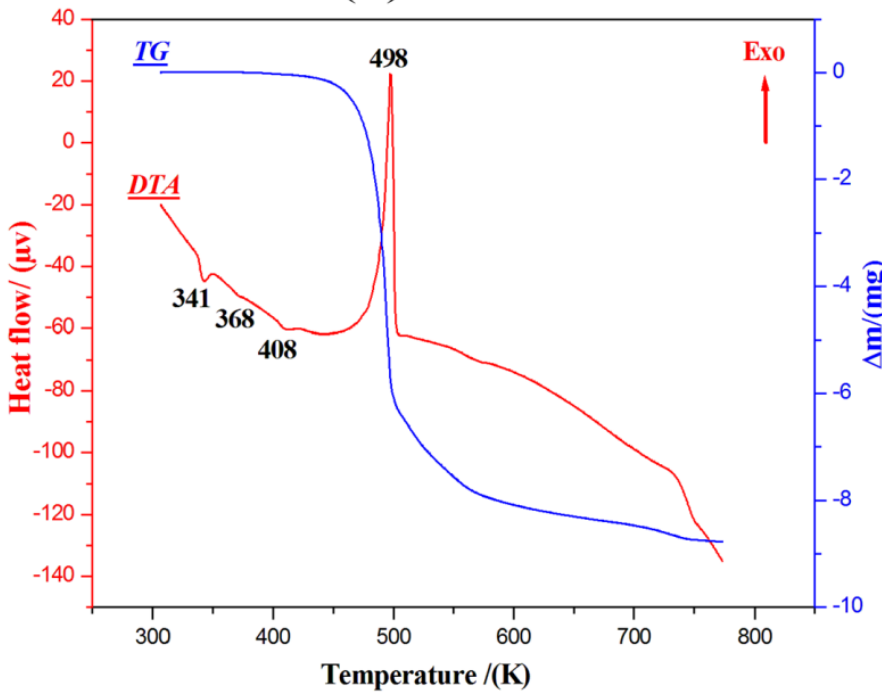

(b)

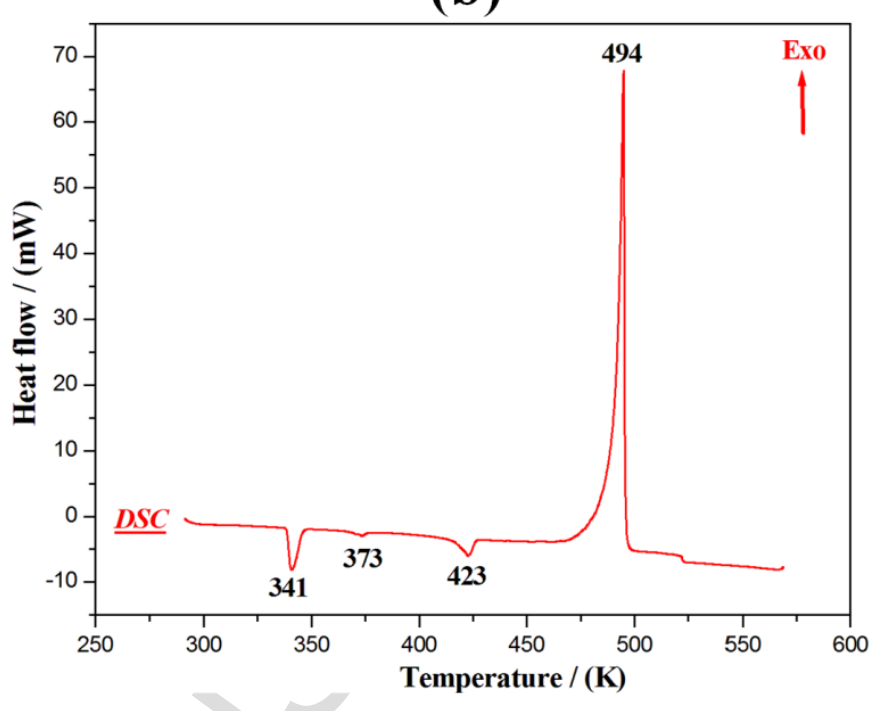

F i g . 10 


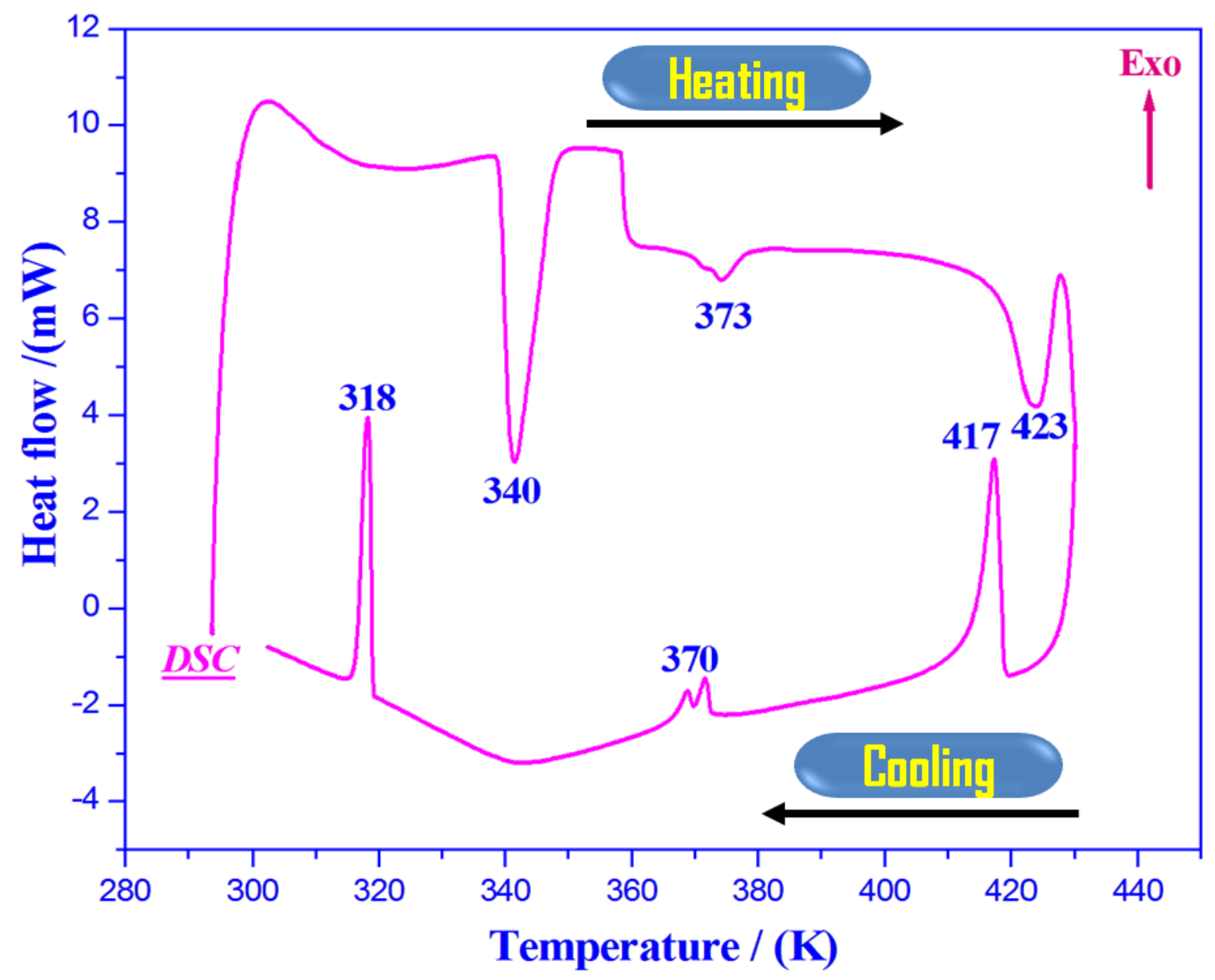

F i g . 11 

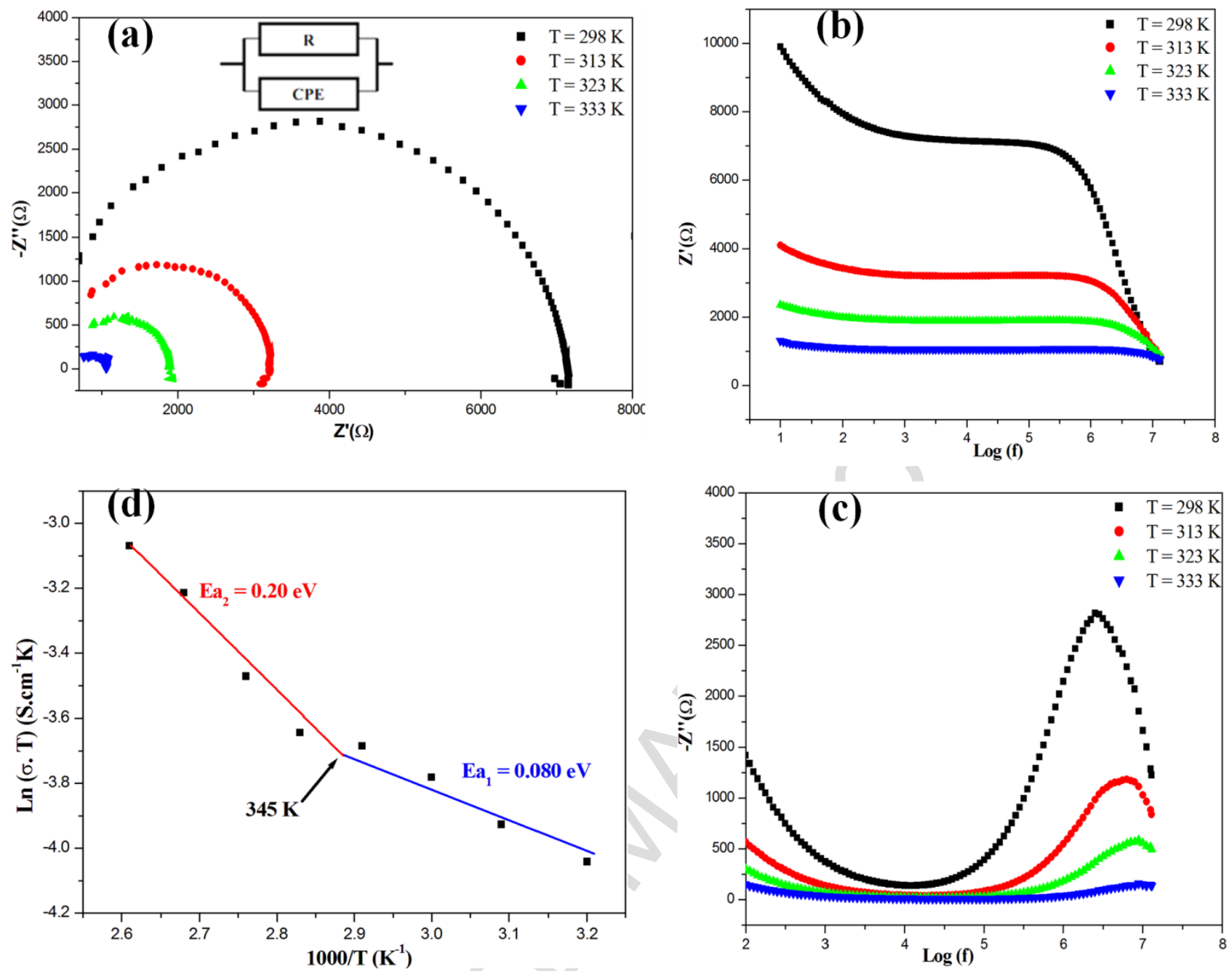

F i g . 12 


\section{Highlights}

- Single crystals of PEAN were grown by slow evaporation-solution growth technique.

- Structural analysis was done by single crystal X-ray diffraction analysis.

- Thermal stability was investigated by thermal analyses.

- FT-IR spectra in the solid phase are recorded and analyzed.

- The optimized geometry and vibrational wavenumbers are computed using DFT method.

- Ionic conductivity was also investigated. 


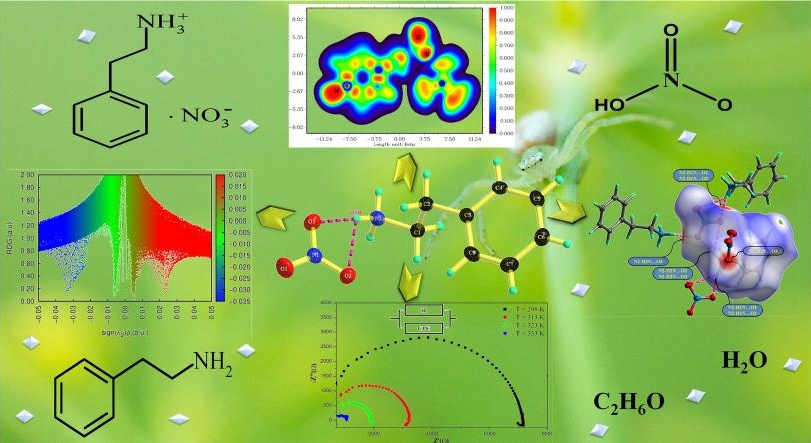


Table 1

\begin{tabular}{ll}
\hline CCDC & 1839301 \\
Temperature & $150 \mathrm{~K}$ \\
Empirical formula & $\mathrm{C}_{8} \mathrm{H}_{12} \mathrm{~N}_{2} \mathrm{O}_{3}$ \\
Formula weight $\left(\mathrm{g} \mathrm{mol}^{-1}\right)$ & 184.20 \\
Crystal system & Monoclinic \\
Space group & $\mathrm{P} 2{ }_{1} / \mathrm{c}$ \\
$\mathrm{a}$ & $5.9497(8) \AA$ \\
$\mathrm{b}$ & $20.494(3) \AA$ \\
$\mathrm{c}$ & $8.4528(11) \AA$ \\
$\beta$ & $113,812(8)^{\circ}$ \\
$\mathrm{Z}$ & 4 \\
$\mathrm{~V}$ & $942.9(2) \AA^{3}$ \\
$\mathrm{~F}(000)$ & 392 \\
$\mu($ Mo K $\alpha)$ & $0.100 \mathrm{~mm}^{-1}$ \\
Index ranges & $-7 \leq \mathrm{h} \leq 5,-26 \leq \mathrm{k} \leq 26,-9 \leq 1 \leq 10$ \\
Reflections collected & 6632 \\
Independent reflections & 2195 \\
Reflections with I $>2 \sigma(\mathrm{I})$ & 1539 \\
$\mathrm{R}_{\text {int }}$ & 0.043 \\
Absorption correction: multi-scan & \\
Refined parameters & 130 \\
$\mathrm{R}\left[\mathrm{F}^{2}>2 \sigma\left(\mathrm{F}^{2}\right)\right]$ & 0.049 \\
wR(F $\left.{ }^{2}\right)$ & 0.125 \\
Goodness of fit & 1.09 \\
$\Delta \rho_{\text {max }} 0.24$ e $\AA^{-3}$ & \\
\hline
\end{tabular}


Table 2

\begin{tabular}{ccccc}
\hline$D-\mathrm{H} \cdots A$ & $D-\mathrm{H}(\AA)$ & $\mathrm{H} \cdots A(\AA)$ & $D \cdots A(\AA)$ & $D-\mathrm{H} \cdots A\left(^{\circ}\right)$ \\
\hline $\mathrm{N} 2-\mathrm{H} 1 \mathrm{~N} \cdots \mathrm{O} 2^{\mathrm{i}}$ & $0.90(2)$ & $2.01(2)$ & $2.890(2)$ & $166.4(18)$ \\
$\mathrm{N} 2-\mathrm{H} 1 \mathrm{~N} \cdots \mathrm{O} 1^{\mathrm{i}}$ & $0.90(2)$ & $2.49(2)$ & $3.208(3)$ & $137.0(17)$ \\
$\mathrm{N} 2-\mathrm{H} 2 \mathrm{~N} \cdots \mathrm{O} 3$ & $0.94(2)$ & $1.88(2)$ & $2.815(2)$ & $178(2)$ \\
$\mathrm{N} 2-\mathrm{H} 2 \mathrm{~N} \cdots \mathrm{O} 2$ & $0.94(2)$ & $2.62(2)$ & $3.254(2)$ & $125.3(17)$ \\
$\mathrm{N} 2-\mathrm{H} 3 \mathrm{~N} \cdots \mathrm{O} 3^{\text {iii }}$ & $0.97(3)$ & $1.93(3)$ & $2.865(2)$ & $159(2)$ \\
$\mathrm{C} 1-\mathrm{H} 1 \mathrm{~A} \cdots \mathrm{Cg}^{\mathrm{iii}}$ & 0.97 & 2.735 & $3.554(2)$ & 142.5 \\
$\mathrm{C} 2-\mathrm{H} 2 \mathrm{~B} \cdots \mathrm{Cg}^{\mathrm{iv}}$ & 0.97 & 2.952 & $3.704(2)$ & 135.2 \\
\hline
\end{tabular}

Symmetry code: : (i) $x-1, y, z$; (ii) $x,-y+1 / 2, z+1 / 2$; (iii) $x-1,-y+1 / 2, z+1 / 2$; (iv) $\mathrm{x}-1,-y+1 / 2$, $\mathrm{z}-1 / 2 ; \mathrm{Cg}$ (gravity center of the ring C3-C4-C5-C6-C7-C8)

Table 3

\begin{tabular}{|c|c|c|c|}
\hline & $\begin{array}{c}\text { B3LYP/6- } \\
311++\mathrm{G}(\mathrm{d}, \mathrm{p})\end{array}$ & B3LYP/6-311++G(3df,3pd) & Exp. \\
\hline O3-N1 & 1.3683 & 1.3636 & 1.2639 \\
\hline $\mathrm{O} 3-\mathrm{H} 2 \mathrm{~N}$ & 1.044 & 1.0386 & 1.8766 \\
\hline $\mathrm{O} 2-\mathrm{N} 1$ & 1.2237 & 1.2196 & 1.2514 \\
\hline O1-N1 & 1.2043 & 1.2014 & 1.2309 \\
\hline $\mathrm{N} 2-\mathrm{C} 1$ & 1.4808 & 1.4764 & 1.4884 \\
\hline N2-H1N & 1.0174 & 1.0149 & 0.9005 \\
\hline $\mathrm{N} 2-\mathrm{H} 2 \mathrm{~N}$ & 1.5996 & 1.6157 & 0.9383 \\
\hline N2-H3N & 1.0175 & 1.0149 & 0.9757 \\
\hline C3-C4 & 1.3991 & 1.3953 & 1.3925 \\
\hline C3-C2 & 1.5129 & 1.5093 & 1.5085 \\
\hline C3-C8 & 1.3993 & 1.3955 & 1.3883 \\
\hline C4-H4 & 1.0859 & 1.0834 & 0.9305 \\
\hline C4-C5 & 1.3937 & 1.39 & 1.3857 \\
\hline C7-H7 & 1.0843 & 1.0818 & 0.9294 \\
\hline C7-C6 & 1.3939 & 1.3902 & 1.3863 \\
\hline C7-C8 & 1.3936 & 1.3899 & 1.3871 \\
\hline $\mathrm{C} 2-\mathrm{H} 2 \mathrm{~A}$ & 1.0963 & 1.0935 & 0.9694 \\
\hline $\mathrm{C} 2-\mathrm{H} 2 \mathrm{~B}$ & 1.0941 & 1.0912 & 0.9696 \\
\hline $\mathrm{C} 2-\mathrm{C} 1$ & 1.5349 & 1.5317 & 1.5191 \\
\hline C1-H1A & 1.0964 & 1.0938 & 0.9701 \\
\hline C1-H1B & 1.0929 & 1.0902 & 0.9702 \\
\hline C5-H5 & 1.0844 & 1.0818 & 0.9294 \\
\hline $\mathrm{C} 5-\mathrm{C} 6$ & 1.3937 & 1.39 & 1.3736 \\
\hline C6-H6 & 1.0841 & 1.0815 & 0.9296 \\
\hline C8-H8 & 1.0856 & 1.0831 & 0.9299 \\
\hline $\mathrm{N} 1-\mathrm{O} 3-\mathrm{H} 2 \mathrm{~N}$ & 107.118 & 106.8928 & 109.9016 \\
\hline $\mathrm{O} 3-\mathrm{N} 1-\mathrm{O} 2$ & 117.1404 & 117.0397 & 118.8534 \\
\hline O3-N1-O1 & 115.4747 & 115.4672 & 119.9664 \\
\hline O2-N1-O1 & 127.3849 & 127.493 & 121.1771 \\
\hline C1-N2-H1N & 110.5172 & 110.6249 & 110.5345 \\
\hline
\end{tabular}




\begin{tabular}{|c|c|c|c|}
\hline C1-N2-H2N & 114.4809 & 114.3752 & 111.0567 \\
\hline C1-N2-H3N & 110.6499 & 110.8219 & 111.2474 \\
\hline H1N-N2-H2N & 112.9704 & 113.2256 & 109.1759 \\
\hline $\mathrm{H} 1 \mathrm{~N}-\mathrm{N} 2-\mathrm{H} 3 \mathrm{~N}$ & 106.9991 & 107.148 & 106.8079 \\
\hline $\mathrm{H} 2 \mathrm{~N}-\mathrm{N} 2-\mathrm{H} 3 \mathrm{~N}$ & 100.5516 & 99.9347 & 107.8794 \\
\hline $\mathrm{C} 4-\mathrm{C} 3-\mathrm{C} 2$ & 120.8862 & 120.9056 & 121.1216 \\
\hline C4-C3-C8 & 118.4454 & 118.3939 & 118.1313 \\
\hline $\mathrm{C} 2-\mathrm{C} 3-\mathrm{C} 8$ & 120.6496 & 120.6793 & 120.7466 \\
\hline C3-C4-H4 & 119.5501 & 119.5182 & 119.5249 \\
\hline C3-C4-C5 & 120.9011 & 120.9423 & 120.948 \\
\hline $\mathrm{H} 4-\mathrm{C} 4-\mathrm{C} 5$ & 119.5468 & 119.5377 & 119.5271 \\
\hline H7-C7-C6 & 120.0874 & 120.106 & 119.9963 \\
\hline $\mathrm{H} 7-\mathrm{C} 7-\mathrm{C} 8$ & 119.7711 & 119.7709 & 119.895 \\
\hline C6-C7-C8 & 120.1408 & 120.1224 & 120.1086 \\
\hline $\mathrm{C} 3-\mathrm{C} 2-\mathrm{H} 2 \mathrm{~A}$ & 109.6094 & 109.6432 & 109.329 \\
\hline $\mathrm{C} 3-\mathrm{C} 2-\mathrm{H} 2 \mathrm{~B}$ & 110.1261 & 110.135 & 109.3446 \\
\hline C3-C2-C1 & 112.1862 & 112.2326 & 111.3027 \\
\hline $\mathrm{H} 2 \mathrm{~A}-\mathrm{C} 2-\mathrm{H} 2 \mathrm{~B}$ & 106.874 & 106.93 & 108.047 \\
\hline $\mathrm{H} 2 \mathrm{~A}-\mathrm{C} 2-\mathrm{C} 1$ & 109.0084 & 108.9109 & 109.3788 \\
\hline $\mathrm{H} 2 \mathrm{~B}-\mathrm{C} 2-\mathrm{C} 1$ & 108.8857 & 108.8371 & 109.3765 \\
\hline $\mathrm{N} 2-\mathrm{C} 1-\mathrm{C} 2$ & 110.8169 & 110.8017 & 110.1046 \\
\hline N2-C1-H1A & 111.7173 & 111.8248 & 109.6634 \\
\hline N2-C1-H1B & 107.5261 & 107.6006 & 109.6678 \\
\hline C2-C1-H1A & 109.7122 & 109.6023 & 109.6221 \\
\hline C2-C1-H1B & 109.7502 & 109.7158 & 109.6153 \\
\hline H1A-C1-H1B & 107.2166 & 107.1957 & 108.1373 \\
\hline C4-C5-H5 & 119.8184 & 119.8172 & 119.8078 \\
\hline C4-C5-C6 & 120.0893 & 120.0724 & 120.335 \\
\hline H5-C5-C6 & 120.0914 & 120.1096 & 119.8572 \\
\hline C7-C6-C5 & 119.5764 & 119.5801 & 119.5697 \\
\hline C7-C6-H6 & 120.2121 & 120.2099 & 120.2206 \\
\hline C5-C6-H6 & 120.2106 & 120.209 & 120.2096 \\
\hline $\mathrm{C} 3-\mathrm{C} 8-\mathrm{C} 7$ & 120.8465 & 120.8884 & 120.905 \\
\hline $\mathrm{C} 3-\mathrm{C} 8-\mathrm{H} 8$ & 119.5336 & 119.5019 & 119.5365 \\
\hline C7-C8-H8 & 119.618 & 119.6081 & 119.5586 \\
\hline
\end{tabular}


Table 4

\begin{tabular}{|c|c|c|c|c|c|c|}
\hline & O3...H1A & O3...H2A & O2...H2N & RCP & NRCP1 & NRCP2 \\
\hline Density of electrons $\rho(\mathbf{r})$ & 0.00619 & 0.00556 & 0.03365 & 0.02356 & 0.0052 & 0.0057 \\
\hline Laplacian of electron density $\nabla^{2} \rho(\mathbf{r})$ & 0.02270 & 0.01860 & 0.08946 & 0.16501 & 0.02130 & 0.02518 \\
\hline Lagrangian kinetic energy G(r) & 2.96942 & 2.49820 & 16.02369 & 21.712721 & 2.65792795 & 3.15495108 \\
\hline Energy density $\mathrm{H}(\mathrm{r})$ & 0.60600 & 0.43177 & -1.93379 & 4.1828072 & 0.68325221 & 0.7946060 \\
\hline Potential energy density V(r) & -2.36343 & -2.06643 & -17.95747 & -17.52991 & -1.974676 & -2.360345 \\
\hline Interaction energy $\left(\mathrm{E}_{\mathrm{int}}\right)$ & -1.18171 & -1.03322 & -8.97874 & & & \\
\hline Electron localization function (ELF) & 0.01587 & 0.01562 & 0.13543 & 0.025115 & 0.010432 & 0.01065 \\
\hline Localized orbital locator (LOL) & 0.11290 & 0.11213 & 0.28363 & 0.13844 & 0.09331 & 0.09418 \\
\hline Local information entropy & 0.00061 & 0.00055 & 0.00274 & 0.002003 & 0.000514 & 0.00057 \\
\hline Reduced density gradient (RDG) & $\begin{array}{c}0.1220810^{-} \\
14\end{array}$ & $\begin{array}{c}0.9763410^{-} \\
15\end{array}$ & $\begin{array}{c}0.1165110^{-} \\
14\end{array}$ & $\begin{array}{c}0.79846710^{-} \\
15\end{array}$ & $\begin{array}{l}0.2306710^{-} \\
14\end{array}$ & $\begin{array}{c}0.2065210^{-} \\
15\end{array}$ \\
\hline Average local ionization energy & 0.45668 & 0.42441 & 0.50993 & 0.70658 & 0.46858 & 050783 \\
\hline Ellipticity $(\varepsilon)$ & 0.25625 & 0.39951 & 0.06388 & -1.2073 & -1.8530 & -1.7866 \\
\hline Eta index $(\zeta)$ & 0.13971 & 0.16475 & 0.27771 & 0.19040 & 0.14145 & 0.14131 \\
\hline
\end{tabular}


Table 5.

\begin{tabular}{|c|c|c|c|c|}
\hline Donor (i) & Acceptor (j) & ${ }^{\mathrm{a}} \mathrm{E}(2)$ & $E(i)-E(j)^{b}$ & $F(i, j)^{c}$ \\
\hline$\pi\left(\mathrm{O}_{1}-\mathrm{N}_{1}\right)$ & $\pi^{*}\left(\mathrm{O}_{1}-\mathrm{N}_{1}\right)$ & 10.05 & 0.55 & 0.078 \\
\hline $\mathrm{LP}\left(\mathrm{O}_{3}\right)$ & $\sigma^{*}\left(\mathrm{O}_{2}-\mathrm{N}_{1}\right)$ & 9.82 & 0.71 & 0.075 \\
\hline $\mathrm{LP}\left(\mathrm{O}_{3}\right)$ & $\sigma^{*}\left(\mathrm{O}_{1}-\mathrm{N}_{1}\right)$ & 15.20 & 0.64 & 0.090 \\
\hline $\mathrm{LP}\left(\mathrm{O}_{3}\right)$ & $\pi^{*}\left(\mathrm{O}_{1}-\mathrm{N}_{1}\right)$ & 47.66 & 0.27 & 0.108 \\
\hline $\mathrm{LP}\left(\mathrm{O}_{2}\right)$ & $\sigma^{*}\left(\mathrm{O}_{3}-\mathrm{N}_{1}\right)$ & 15.36 & 0.65 & 0.089 \\
\hline $\mathrm{LP}\left(\mathrm{O}_{2}\right)$ & $\sigma^{*}\left(\mathrm{O}_{1}-\mathrm{N}_{1}\right)$ & 14.40 & 0.60 & 0.086 \\
\hline $\mathrm{LP}\left(\mathrm{O}_{2}\right)$ & $\pi *\left(\mathrm{O}_{1}-\mathrm{N}_{1}\right)$ & 55.10 & 0.26 & 0.112 \\
\hline $\operatorname{LP}\left(\mathrm{O}_{1}\right)$ & $\sigma^{*}\left(\mathrm{O}_{3}-\mathrm{N}_{1}\right)$ & & 0.63 & 0.097 \\
\hline $\mathrm{LP}\left(\mathrm{O}_{1}\right)$ & $\sigma^{*}\left(\mathrm{O}_{2}-\mathrm{N}_{1}\right)$ & 17.51 & 0.66 & 0.096 \\
\hline$\pi^{*}\left(\mathrm{O}_{1}-\mathrm{N}_{1}\right)$ & $\sigma^{*}\left(\mathrm{O}_{1}-\mathrm{N}_{1}\right)$ & 71.79 & 0.33 & 0.223 \\
\hline $\mathrm{LP}\left(\mathrm{O}_{3}\right)$ & $\sigma^{*}\left(\mathrm{~N}_{2}-\mathrm{H}_{2 \mathrm{~N}}\right)$ & 14.04 & 0.78 & 0.094 \\
\hline$\pi\left(\mathrm{C}_{3}-\mathrm{C}_{4}\right)$ & $\pi^{*}\left(\mathrm{C}_{7}-\mathrm{C}_{8}\right)$ & 19.99 & 0.29 & 0.068 \\
\hline$\pi\left(\mathrm{C}_{3}-\mathrm{C}_{4}\right)$ & $\pi^{*}\left(\mathrm{C}_{5}-\mathrm{C}_{6}\right)$ & 20.17 & 0.29 & 0.069 \\
\hline$\pi\left(\mathrm{C}_{7}-\mathrm{C}_{8}\right)$ & $\pi *\left(\mathrm{C}_{3}-\mathrm{C}_{4}\right)$ & 22.22 & 0.28 & 0.071 \\
\hline$\pi\left(\mathrm{C}_{7}-\mathrm{C}_{8}\right)$ & & 20.03 & 0.29 & 0.068 \\
\hline$\pi\left(\mathrm{C}_{5}-\mathrm{C}_{6}\right)$ & $\left(\mathrm{C}_{3}-\mathrm{C}_{4}\right)$ & 20.36 & 0.28 & 0.068 \\
\hline$\pi\left(\mathrm{C}_{5}-\mathrm{C}_{6}\right)$ & $\pi *\left(C_{7}-C_{8}\right)$ & 20.20 & 0.29 & 0.068 \\
\hline
\end{tabular}

${ }^{a} \mathrm{E}(2)$ means energy of hyper conjugate interactions(stabilization energy in Kcal $/ \mathrm{mol}$ ).

${ }^{b}$ Energy difference between donor and acceptor i and j NBO orbitals in a.u.

${ }^{c} \mathrm{~F}(\mathrm{i}, \mathrm{j})$ is the Fock matrix element between $\mathrm{i}$ and $\mathrm{j}$ NBO orbitals in a.u. 
Table 6.

\begin{tabular}{ccccccc}
\hline $\begin{array}{c}\text { Number } \\
\text { of surface } \\
\text { minima }\end{array}$ & a.u & $\mathrm{eV}$ & $\mathrm{Kcal} / \mathrm{mol}$ & \multicolumn{3}{c}{$\mathrm{X} / \mathrm{Y} / \mathrm{Z}$ coordinate(Angstrom) } \\
\hline 1 & -0.00522338 & -0.142135 & -3.277721 & -3.740211 & 0.175737 & 1.827884 \\
2 & -0.01406535 & -0.382738 & -8.826148 & -2.343773 & -2.038873 & -1.372020 \\
3 & -0.09900615 & -2.694094 & -62.127347 & 3.343670 & -2.947025 & 0.592511 \\
4 & -0.09691886 & -2.637296 & -60.817551 & 5.162916 & -0.343579 & -1.602288 \\
\hline $\begin{array}{c}\text { Number } \\
\text { of surface }\end{array}$ & $\mathrm{a} . \mathrm{u}$ & $\mathrm{eV}$ & $\mathrm{Kcal} / \mathrm{mol}$ & $\mathrm{X} / \mathrm{Y} / \mathrm{Z}$ coordinate(Angstrom) \\
maxima & & & & & & \\
\hline 1 & 0.03026541 & 0.823564 & 18.991849 & -6.168387 & -1.885104 & 0.326353 \\
2 & 0.02967241 & 0.807427 & 18.619735 & -5.960049 & -0.346093 & -0.497468 \\
3 & 0.03326189 & 0.905102 & 20.872169 & -5.757719 & 1.376247 & -1.446149 \\
4 & 0.02701755 & 0.735185 & 16.953785 & -4.574122 & -2.672136 & 1.096269 \\
5 & 0.02703892 & 0.735766 & 16.967192 & -3.441940 & -3.399866 & 1.781505 \\
6 & 0.13218519 & 3.596942 & 82.947528 & 1.087223 & 3.935644 & -0.082410 \\
7 & 0.12700403 & 3.455955 & 79.696296 & 2.147701 & 2.857330 & 2.561221 \\
8 & -0.03031125 & -0.824811 & -19.020615 & 2.273719 & -1.126966 & -1.541740 \\
\hline
\end{tabular}


Table 7.

\begin{tabular}{|c|c|c|c|c|}
\hline \multirow{2}{*}{ Exp. } & \multicolumn{4}{|c|}{ B3LYP/6-311++G(d,p) Method } \\
\hline & Unscaled & Scaled & $\mathrm{I}^{\mathrm{i}}$ & Vibrational assignments (\% PED) \\
\hline 3453 & 3553 & 3492 & 14.14 & $v \mathrm{NH} 100$ \\
\hline 3267 & 3480 & 3421 & 5.29 & vNH 99 \\
\hline 3200 & 3195 & 3141 & 13.33 & vCH 92 \\
\hline 3100 & 3184 & 3129 & 25.84 & vCH 85 \\
\hline 3056 & 3174 & 3120 & 4.27 & vCH 91 \\
\hline 3018 & 3162 & 3108 & 5.64 & $v \mathrm{CH} 84$ \\
\hline 2936 & 3158 & 3104 & 9.59 & $v \mathrm{CH} 85$ \\
\hline 2789 & 3086 & 3034 & 25.3 & vCH 87 \\
\hline 2696 & 3066 & 3014 & 6.2 & vCH 90 \\
\hline 2602 & 3022 & 2971 & 39.28 & vCH 78 \\
\hline 2509 & 3014 & 2963 & 12.48 & vCH 96 \\
\hline 2373 & 2470 & 2428 & 2790.85 & vOH 97 \\
\hline 2205 & 1728 & 1699 & 123.75 & $v \mathrm{ON} 47 \quad \beta \mathrm{HON} 30$ \\
\hline 2162 & 1646 & 1577 & 52.94 & $\delta$ HNHC $55 \quad \beta$ HNH 40 \\
\hline 2050 & 1644 & 1575 & 4.58 & $v C C 65 \quad \beta$ HCC 20 \\
\hline 1982 & 1622 & 1553 & 1.02 & $v \mathrm{CC} 65 \quad \beta \mathrm{HCC} 11$ \\
\hline 1758 & 1530 & 1466 & 501.19 & $\beta$ HCC $62 \quad \beta C C C ~ 16$ \\
\hline 1640 & 1525 & 1461 & 9.75 & $v O N 32 \quad \beta H O N 19 \quad \beta H C H 21 \quad \gamma \mathrm{OCNH} 10$ \\
\hline 1547 & 1520 & 1456 & 28.6 & $v \mathrm{ON} 12 \quad \beta \mathrm{HCH} 61$ \\
\hline 1497 & 1495 & 1432 & 7.92 & $\beta \mathrm{HCH} 87$ \\
\hline 1392 & 1486 & 1424 & 6.94 & $\beta \mathrm{HCC} 52 \quad v C C 16$ \\
\hline 1348 & 1416 & 1357 & 20.25 & $\delta \mathrm{HCHN} 50 \quad \beta \mathrm{HCC} 22$ \\
\hline 1317 & 1366 & 1309 & 0.4 & $\beta \mathrm{HCC} 86$ \\
\hline 1156 & 1354 & 1297 & 0.64 & $\delta$ HCCC $49 \delta$ HNHC 10 \\
\hline 1106 & 1341 & 1284 & 0.11 & $\nu$ CC $57 \quad \beta$ HCC 25 \\
\hline 1037 & 1324 & 1269 & 28.81 & vON $52 \beta \mathrm{HCC} 13$ \\
\hline 963 & 1322 & 1266 & 455.26 & $v \mathrm{ON} 30 \quad \beta \mathrm{HCC} 31$ \\
\hline 827 & 1269 & 1215 & 1.31 & $\delta \mathrm{HCCC} 28$ \\
\hline 746 & 1224 & 1173 & 0.3 & $\beta \mathrm{HCC} 14 \quad v C C 40$ \\
\hline 702 & 1205 & 1155 & 1.38 & vCC $22 \quad \beta$ HCC 70 \\
\hline 597 & 1188 & 1138 & 114 & $\beta \mathrm{HNH} 47 \quad \gamma \mathrm{OCNH} 11$ \\
\hline \multirow[t]{15}{*}{491} & 1184 & 1134 & 0.57 & $v \mathrm{CC} 12 \quad \beta \mathrm{HCC} 71$ \\
\hline & 1162 & 1114 & 24.46 & $\delta$ HNHC $26 \quad \beta$ HCC $15 \quad \beta$ HNH 13 \\
\hline & 1118 & 1071 & 17.34 & $\beta \mathrm{HCC} 33 \quad v \mathrm{CC} 13$ \\
\hline & 1067 & 1022 & 9.31 & $\beta \mathrm{HCC} 22 \quad v \mathrm{CC} 38$ \\
\hline & 1051 & 1007 & 6.11 & $\beta \mathrm{HCC} 17 \quad v C C \quad 41 \quad \beta C C C 24$ \\
\hline & 1041 & 997 & 30.05 & $v \mathrm{CC} 10 \quad v \mathrm{NC} 56$ \\
\hline & 1014 & 971 & 0.62 & $\nu$ CC $19 \quad \beta$ CCC $24 \quad \delta$ HCCC 36 \\
\hline & 1012 & 969 & 0.02 & $v$ CC $14 \quad \beta C C C ~ 18 \quad \delta$ НCCC 45 \\
\hline & 995 & 953 & 0.03 & $\delta \mathrm{HCCC} 83$ \\
\hline & 973 & 932 & 9.34 & $v C C 29 \delta$ HCCC 13 \\
\hline & 965 & 924 & 159.18 & $\nu \mathrm{ON} 46 \quad \beta O N O 22$ \\
\hline & 930 & 891 & 119.72 & $\delta$ HNHC $13 \quad \delta$ HCCC $13 \quad \beta$ HNH 26 \\
\hline & 928 & 889 & 6.42 & $\delta \mathrm{HCCC} 66$ \\
\hline & 863 & 827 & 0.06 & $\delta \mathrm{HCCC} 98$ \\
\hline & 832 & 798 & 4.42 & $v C C 19 \quad \beta C C C 45$ \\
\hline
\end{tabular}




\begin{tabular}{|c|c|c|c|}
\hline 806 & 772 & 11.68 & $\gamma \mathrm{OOON} 99$ \\
\hline 791 & 758 & 2.52 & $\delta$ HCHN $11 \quad \delta$ HCCC 62 \\
\hline 766 & 734 & 33.52 & $\delta \mathrm{HCCC} 57$ \\
\hline 711 & 681 & 42.91 & $\delta \mathrm{HCCC} 24 \delta \mathrm{CCCC} 49$ \\
\hline 697 & 667 & 6.14 & vON $33 \quad \beta O N O 55$ \\
\hline 668 & 640 & 10.15 & BONO 69 \\
\hline 636 & 609 & 0.02 & $\nu C C 11 \quad \beta C C C 79$ \\
\hline 607 & 582 & 11.05 & $\beta C C N 49$ \\
\hline 514 & 492 & 19.06 & $\gamma \operatorname{CCCC~} 57 \quad \beta C C C 11$ \\
\hline 465 & 446 & 15.16 & $\delta$ HNHC $14 \quad \beta \mathrm{HNH} 43$ \\
\hline 415 & 397 & 0 & $\delta \mathrm{HCCC} 17 \delta \mathrm{CCCC} 72$ \\
\hline 349 & 334 & 1.94 & $\beta C C C 67$ \\
\hline 315 & 301 & 5.07 & $v C C \quad 10 \quad \beta C C N \quad 10 \quad \beta$ HNH 40 \\
\hline 288 & 276 & 20.98 & $\beta C C C 30 \quad v N H 18 \quad \gamma C C C C 18$ \\
\hline 254 & 244 & 53.75 & vNH 56 \\
\hline 150 & 144 & 5.28 & $\beta \mathrm{HON} 10 \quad \delta \mathrm{CCCN} 38$ \\
\hline 101 & 97 & 0.92 & $\beta$ HNH $11 \quad \beta C C C 20 \quad \gamma$ CCCC $19 \gamma$ OCNH 18 \\
\hline 98 & 94 & 1.8 & $\beta C C C 12 \quad v N H 12 \gamma C C C C 13 \quad \gamma \mathrm{OCNH} 16$ \\
\hline 76 & 72 & 0.53 & $\delta \mathrm{HONO} 70$ \\
\hline 54 & 52 & 0.19 & $\delta$ HNCC 63 \\
\hline 31 & 30 & 0.36 & $\delta \mathrm{CCCN} 20 \quad \beta \mathrm{HNC} 37 \quad \delta \mathrm{CHON} 26$ \\
\hline 23 & 22 & 0.99 & $\delta \mathrm{HNCC} 76$ \\
\hline 11 & 10 & 2.01 & $\beta \mathrm{HNC} 16 \quad \delta \mathrm{CHON} 66$ \\
\hline
\end{tabular}

$\mathrm{I}^{\mathrm{i}}$ : infrared intensity $\left(\mathrm{km} \cdot \mathrm{mol}^{-1}\right), v, \beta, \delta$ and $\gamma$ denote stretching, in-plane bending, torsion and Out-of-plane bending modes, respectively. PED: potential energy distribution data are taken fromVEDA4.

aScaling factor: from 4000 to $1700 \mathrm{~cm}^{-1}$ are scaled with 0.983 and lower than $1700 \mathrm{~cm}^{-1}$ are scaled with 0.958 , 